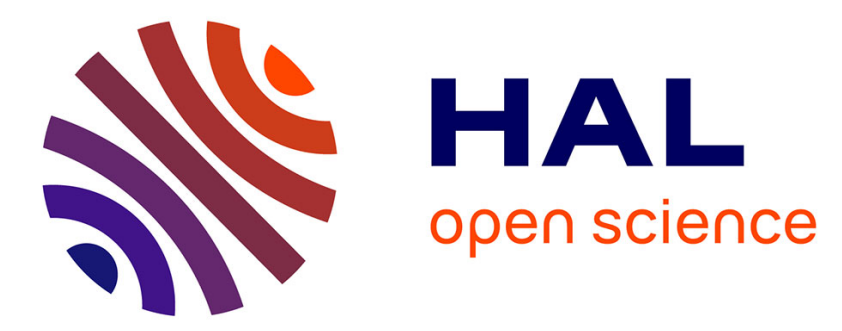

\title{
Dissection optique du rôle des récepteurs nicotiniques neuronaux à l'aide de récepteurs photo-contrôlables
}

Romain Durand-de Cuttoli, Sarah Mondoloni, Alexandre Mourot

\section{To cite this version:}

Romain Durand-de Cuttoli, Sarah Mondoloni, Alexandre Mourot. Dissection optique du rôle des récepteurs nicotiniques neuronaux à l'aide de récepteurs photo-contrôlables. Biologie Aujourd'hui, 2017, 211 (2), pp.173 - 188. 10.1051/jbio/2017022 . hal-01688455

\section{HAL Id: hal-01688455 \\ https://hal.sorbonne-universite.fr/hal-01688455}

Submitted on 19 Jan 2018

HAL is a multi-disciplinary open access archive for the deposit and dissemination of scientific research documents, whether they are published or not. The documents may come from teaching and research institutions in France or abroad, or from public or private research centers.
L'archive ouverte pluridisciplinaire HAL, est destinée au dépôt et à la diffusion de documents scientifiques de niveau recherche, publiés ou non, émanant des établissements d'enseignement et de recherche français ou étrangers, des laboratoires publics ou privés. 


\title{
Dissection optique du rôle des récepteurs nicotiniques neuronaux à l'aide de récepteurs photo-contrôlables
}

\author{
Romain Durand-de Cuttoli, Sarah Mondoloni, et Alexandre Mourot* \\ Sorbonne Universités, UPMC Univ Paris 06, INSERM, CNRS, Neuroscience Paris Seine-Institut de Biologie Paris Seine \\ (NPS-IBPS), 75005 Paris, France
}

\begin{abstract}
Résumé - Les récepteurs nicotiniques de l'acétylcholine (nAChR) sont des récepteurs canaux largement distribués dans le système nerveux central (SNC) et en périphérie. Les nAChR neuronaux jouent un rôle modulateur important dans l'apprentissage, la mémoire et l'attention, et sont impliqués dans de nombreuses pathologies aussi variées que la maladie d'Alzheimer, la maladie de Parkinson, l'épilepsie, la schizophrénie ou encore l'addiction à la nicotine. L'acétylcholine, neurotransmetteur endogène, et la nicotine, alcaloïde du tabac, entraînent l'ouverture du canal et permettent le passage de cations à travers la membrane plasmique, influençant ainsi l'excitabilité neuronale et la plasticité synaptique. La grande diversité des nAChR neuronaux en termes d'assemblage moléculaire (sous-unités $\alpha 2-10$ et $\beta 2-4$ ), de localisation tissulaire (cortex, mésencéphale, striatum...) mais aussi sub-cellulaire (pré- vs post-synaptique, dendritique $v s$ axonale...) contribue aux rôles variés qu'ont ces récepteurs. Pouvoir activer ou inhiber spécifiquement un sous-type de nAChR à un endroit et un instant voulus permettrait d'avancer considérablement dans la compréhension de ses différents rôles physiologiques et pathologiques. À cette fin sont développées des techniques innovantes de pharmacologie optogénétique qui permettent de contrôler optiquement des sous-types de nAChR endogènes. L'idée est de greffer un nano-interrupteur chimique sur un nAChR modifié génétiquement afin d'utiliser la lumière pour photo-contrôler spécifiquement et précisément ce récepteur modifié. Nous discuterons ici de l'historique de la technique, mais aussi des dernières avancées technologiques dans le contrôle optique de récepteurs endogènes et dans la mise en œuvre de ces outils in vivo.
\end{abstract}

Mots clés : acétylcholine, nicotine, addiction, optogénétique, photopharmacologie

\begin{abstract}
Optically dissecting brain nicotinic receptor function with photo-controllable designer receptors. Nicotinic acetylcholine receptors (nAChRs) are pentameric ligand-gated ion channels widely expressed in the central nervous system and the periphery. They play an important modulatory role in learning, memory and attention, and have been implicated in various diseases such as Alzheimer's disease, Parkinson's disease, epilepsy, schizophrenia and addiction. These receptors are activated by the endogenous neurotransmitter acetylcholine, or by nicotine, the alkaloid found in tobacco leaves. Both molecules open the ion channel and cause the movement of cations across the membrane, which directly affects neuronal excitability and synaptic plasticity. nAChRs are very heterogeneous in their subunit composition ( $\alpha 2-10$ et $\beta 2-$ 4 ), in their brain distribution (cortex, midbrain, striatum...) and in their sub-cellular localization (pre- $v s$ postsynaptic, axonal, dendritic...). This heterogeneity highly contributes to the very diverse roles these receptors have in health and disease. The ability to activate or block a specific nAChR subtype, at a defined time and space within the brain, would greatly help obtaining a clearer picture of these various functions. To this aim, we are developing novel optogenetic pharmacology strategies for optically controlling endogenous nAChR isoforms within the mouse brain. The idea is to tether a chemical photoswitch on the surface of a cysteine-modified $\mathrm{nAChR}$, and use light for rapidly and reversibly turning that receptor mutant on and off. Here we will discuss the history of optogenetic pharmacology, and the recent advances for the optical control of brain nicotinic receptors in vivo.
\end{abstract}

Keywords: acetylcholine, nicotine, addiction, optogenetics, photopharmacology

\footnotetext{
*Auteur de correspondance : almourot@gmail.com
} 


\section{Abréviations}

$\begin{array}{ll}\text { 18-MC } & \text { 18-Méthoxycoronaridine } \\ \text { ACh } & \text { Acétylcholine } \\ \text { AChBP } & \text { Acetylcholine binding protein } \\ \text { ATV } & \text { Aire tegmentale ventrale } \\ \text { CCh } & \text { Carbamylcholine } \\ \text { Ch } & \text { Choline } \\ \text { DHßE } & \text { DiHydro- } \beta \text {-érythrö̈dine } \\ \text { DTT } & \text { Dithiothréitol } \\ \text { IPN } & \text { Noyau interpédonculaire } \\ \text { LPA } & \text { Ligand photochromique attachable } \\ \text { LinAChR } & \text { Light-controlled nicotinic acetylcholine recep- } \\ & \text { tor } \\ \text { MAACh } & \text { Maléimide-azobenzène-acétylcholine } \\ \text { MAHoCh } & \text { Maléimide-azobenzène-homocholine } \\ \text { MEC } & \text { Mécamylamine } \\ \text { mHb } & \text { Habénula médiale } \\ \text { MLA } & \text { Méthylylcaconitine } \\ \text { nAChR } & \text { Récepteur nicotinique de l'acétylcholine } \\ \text { PTA } & \text { Phényltriméthylammonium } \\ \text { SNC } & \text { Système nerveux central } \\ \text { TMA } & \text { Tétraméthylammonium } \\ \text { UV } & \text { Ultraviolet } \\ & \end{array}$

\section{Introduction}

Disséquer les fonctions neuronales des récepteurs et canaux ioniques membranaires, en conditions normales et pathologiques, représente actuellement un défi majeur en neurosciences. De nombreux troubles neuropsychiatriques ou neurodégénératifs ont en effet comme origine un dysfonctionnement au niveau moléculaire de ces protéines membranaires. Des manipulations génétiques et pharmacologiques de ces protéines, entreprises ces dernières années, ont permis des avancées notables dans la compréhension de leurs fonctions physiologiques. La génétique (mutations, délétions, chimères...) permet notamment d'étudier de manière spécifique, et potentiellement avec une précision anatomique, le rôle d'un soustype de récepteur in vivo (Tableau 1). Cependant, la manipulation génétique n'a pas la résolution temporelle suffisante pour permettre d'établir un lien direct entre l'activation des récepteurs, la modulation de circuits neuronaux et la mise en place de comportements. De plus, elle peut conduire à des altérations développementales qui se superposent à celles induites par la délétion/mutation du récepteur. La pharmacologie classique offre une meilleure résolution temporelle, mais souffre d'un problème de sélectivité fonctionnelle, car elle ne peut que rarement être dirigée contre un sous-type de récepteur, et en aucun cas être dirigée sur un type cellulaire précis. Il semble donc crucial de développer des technologies qui combinent les avantages de la pharmacologie et de la génétique afin de contrôler, in vivo, l'activité d'un type de récepteur donné, dans un tissu ciblé, et ce de manière aiguë, idéalement avec une résolution temporelle qui rivalise avec celle de la transmission synaptique (ms).
L'avènement des techniques optogénétiques, et notamment l'utilisation d'opsines microbiennes, est en train de révolutionner la façon dont on étudie les circuits neuronaux (Deisseroth, 2015; Kim et al., 2017). Ces techniques permettent de contrôler l'activité de populations neuronales et leurs projections avec une très grande précision génétique, anatomique et temporelle (Tableau 1). Elles reposent sur l'utilisation de canaux ioniques et transporteurs photosensibles bactériens, que l'on introduit génétiquement dans une population neuronale donnée. L'optogénétique «classique» a ainsi permis de tester de nombreuses hypothèses de lien causal entre activité d'un réseau neuronal et mise en place de comportements. Cependant, cette technique utilise des protéines bactériennes exogènes et ne permet pas de comprendre comment les circuits neuronaux opèrent au niveau moléculaire. Il est donc crucial de développer de nouveaux outils optiques permettant, non pas de contrôler l'activité d'un réseau de neurones, mais de contrôler, au niveau moléculaire, l'activité de récepteurs et canaux naturellement présents dans ces neurones. Ces outils seront notamment indispensables au développement de nouvelles stratégies thérapeutiques ciblant ces récepteurs et canaux. Les techniques de photopharmacologie et de pharmacologie optogénétique présentées dans cette revue utilisent des ligands photochromiques (ou photoswitchs) afin de contrôler optiquement des récepteurs et canaux ioniques neuronaux endogènes.

La photopharmacologie (ou optopharmacologie) repose sur l'utilisation de ligands photochromiques diffusibles, qui changent de forme sous l'action de la lumière (Figure 1). Deux longueurs d'ondes distinctes $\left(h v_{1}\right.$ et $\left.h v_{2}\right)$ sont utilisées pour que le ligand passe, réversiblement et rapidement, d'une configuration étendue à une configuration repliée. Une seule des deux configurations peut se lier au récepteur, et ainsi la lumière va dicter la liaison/dissociation du ligand avec son récepteur. Cette stratégie permet donc de contrôler de manière réversible et rapide (Tableau 1) l'activité de protéines endogènes (pour revues voir: Kramer et al., 2013; Lerch et al., 2016; Berlin \& Isacoff, 2017). La photopharmacologie a été utilisée sur des protéines membranaires aussi variées que des canaux ioniques voltage-dépendants (Banghart et al., 2009; Mourot et al., 2011, 2012, 2017), des canaux sensibles à la température (Stein et al., 2013; Frank et al., 2015), des récepteurs canaux (Deal et al., 1969; Volgraf et al., 2007 ; Stein et al., 2012; Yue et al., 2012; Laprell et al., 2015; Lerch et al., 2016), des canaux activés par les protéines $\mathrm{G}$ (Barber et al., 2016), des canaux constitutivement ouverts (Schönberger et al., 2014), des récepteurs couplés aux protéines G (Nargeot et al., 1982 ; Schönberger \& Trauner, 2014; Zussy et al., 2016) ou des transporteurs de neurotransmetteurs (Quandt et al., 2014). Certains de ces photoswitchs ont été utilisés in vivo chez le rongeur, notamment pour restaurer la sensibilité à la lumière à des rétines aveugles (Polosukhina et al., 2012; Tochitsky et al., 2014) ou encore pour moduler la sensation de la douleur (Mourot et al., 2012; Zussy et al., 2016). Les 
Tableau 1. Principes, avantages et limites pour l'utilisation invivo des différentes techniques génétiques, optiques et pharmacologiques.

\begin{tabular}{|c|c|c|c|c|c|}
\hline & Principe & $\begin{array}{l}\text { Spécificité } \\
\text { pharmacologique }\end{array}$ & $\begin{array}{l}\text { Ciblage } \\
\text { cellulaire } \\
\end{array}$ & $\begin{array}{l}\text { Résolution } \\
\text { spatiale }\end{array}$ & $\begin{array}{l}\text { Résolution } \\
\text { temporelle } \\
\end{array}$ \\
\hline Pharmacologie & Activation/inhibition de récepteurs & Sélective & Impossible & Faible $^{1}$ & $\mathrm{~s}-\mathrm{h}^{2}$ \\
\hline Génétique & Délétion/mutation de récepteurs & Spécifique & Possible & Faible $^{3}$ & Aucune $^{4}$ \\
\hline Optogénétique & Activation/inhibition de neurones & Aucune & Possible & Excellente (optique) & $\mathrm{ms}$ \\
\hline Photo-Pharmacologie & Activation/inhibition de récepteurs & Sélective & Impossible & Excellente (optique) & $\mathrm{ms}$ \\
\hline Pharmacologie optogénétique & Activation/inhibition de récepteurs & Spécifique & Possible & Excellente (optique) & $\mathrm{ms}$ \\
\hline
\end{tabular}

${ }^{1}$ Injection locale techniquement difficile.

${ }^{2}$ Réversibilité limitée par la pharmacocinétique de la drogue; s: seconde ; h: heure.

${ }^{3}$ Sauf pour les expressions conditionnelles (type Cre/Lox).

${ }^{4}$ Sauf pour les systèmes inductibles (type Tet-off/on).

\section{PHARMACOLOGIE}

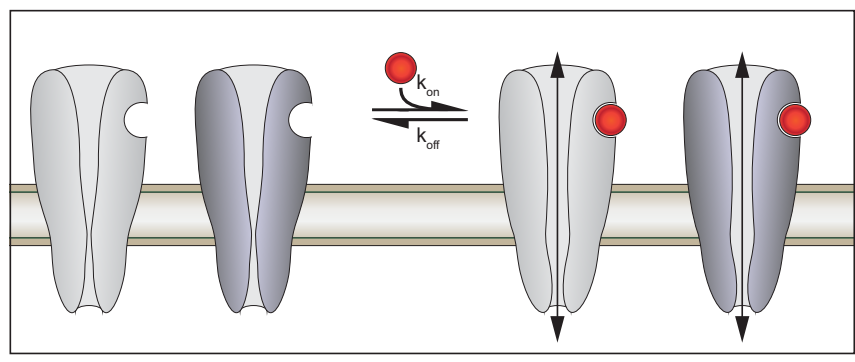

PHOTO-PHARMACOLOGIE

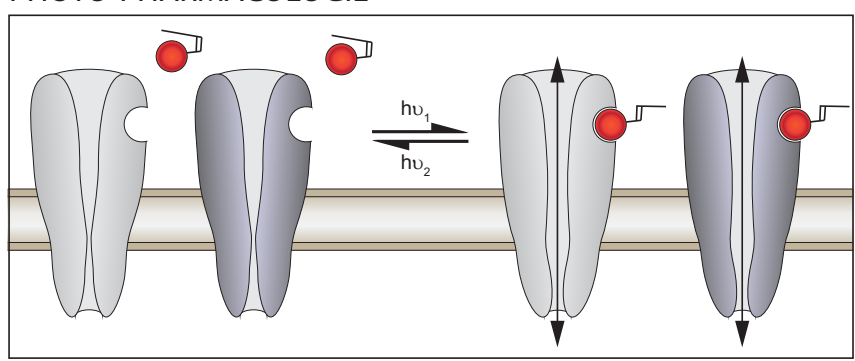

PHARMACOLOGIE OPTOGENETIQUE

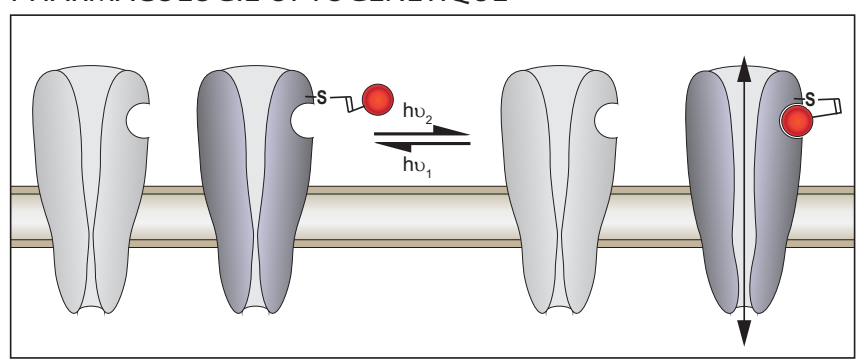

Figure 1. Pharmacologie, photopharmacologie et pharmacologie optogénétique. La pharmacologie classique souffre d'un manque de sélectivité et est limitée par les cinétiques de diffusion des molécules ( $\mathrm{k}_{\mathrm{on}}, \mathrm{k}_{\mathrm{off}}$ et pharmacocinétiques). La photopharmacologie repose sur l'utilisation de ligands photochromiques, qui changent de forme en fonction de la longueur d'onde $(h v)$. Elle permet d'avoir un contrôle spatial et temporel sur l'activité biologique du récepteur, mais souffre d'un manque de sélectivité. La pharmacologie optogénétique permet le contrôle optique d'un sous-type de récepteur particulier, de par l'ancrage du photoswitch sur un résidu muté en cystéine à la surface du récepteur. Deux longueurs d'onde différentes (hv1 et hv2) sont utilisées pour présenter ou retirer le ligand de son site de liaison. composés cagés, qui libèrent un neurotransmetteur sous l'action de la lumière (Ellis-Davies, 2007), sont un autre type de composés photo-pharmacologiques, mais dont l'activation est irréversible, et ne seront pas traités ici.

La pharmacologie optogénétique (ou optogénétique chimique), quant à elle, repose sur l'ancrage covalent d'un ligand photochromique sur un récepteur génétiquement modifié (Kramer et al., 2013; Berlin \& Isacoff, 2017). L'introduction d'un résidu cystéine à la surface de la protéine permet l'attachement covalent d'un photoswitch à proximité du site de liaison du ligand (Figure 1). La pharmacologie optogénétique, en plus de la précision spatio-temporelle qu'offre la photopharmacologie, offre donc une spécificité pharmacologique et génétique: seul le mutant cystéine sera rendu photosensible après attachement du ligand photochromique (Tableau 1). La pharmacologie optogénétique a été appliquée à des canaux ioniques (Banghart et al., 2004; Fortin et al., 2011; Sandoz et al., 2012), des récepteurs canaux (Volgraf et al., 2005; Szobota et al., 2007; Janovjak et al., 2010 ; Tochitsky et al., 2012 ; Lin et al., 2014, 2015 ; Berlin et al., 2016) et des récepteurs couplés aux protéines G (Levitz et al., 2013). C'est une technique exigeante, notamment in vivo, car elle nécessite d'introduire un gène et de délivrer le ligand photochromique et la lumière de manière locale. Néanmoins, des stratégies émergent afin de déployer ces nouveaux outils chez l'animal, notamment chez le poisson zèbre (Wyart et al., 2009; Janovjak et al., 2010; Levitz et al., 2013) et le rongeur (Caporale et al., 2009; Lin et al., 2015; Levitz et al., 2016).

Un avantage certain de la photopharmacologie est qu'elle ne nécessite pas de manipulation génétique, et permet donc de photo-sensibiliser un tissu biologique en quelques minutes. De son côté, la pharmacologie optogénétique nécessite de manipuler génétiquement les tissus, mais offre une spécificité pharmacologie et génétique sans précédent. Dans cette revue nous nous focaliserons sur les stratégies de photopharmacologie et de pharmacologie optogénétique appliquées aux récepteurs nicotiniques. Nous discuterons des possibilités qu'offrent ces outils, mais aussi des défis que représente la mise en œuvre de ces technologies in vivo chez le rongeur. 
A

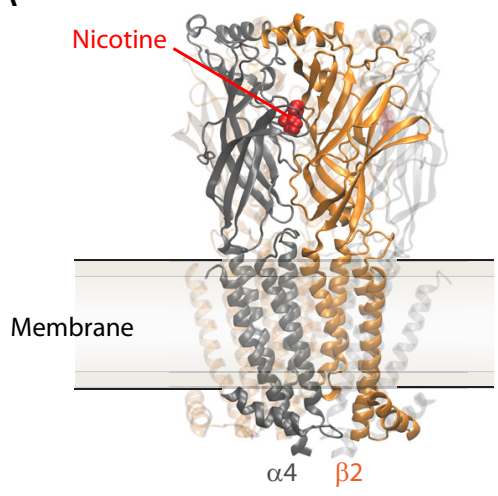

B

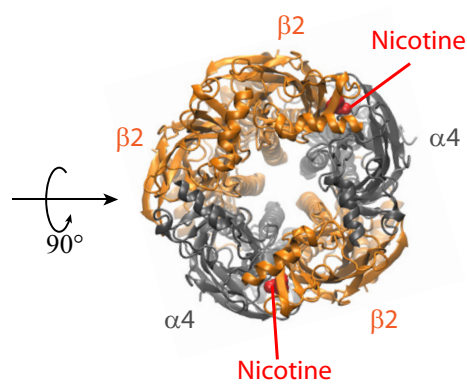

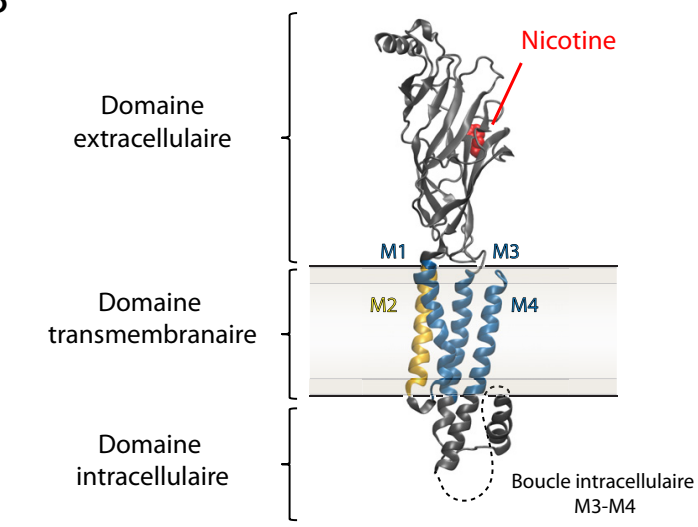
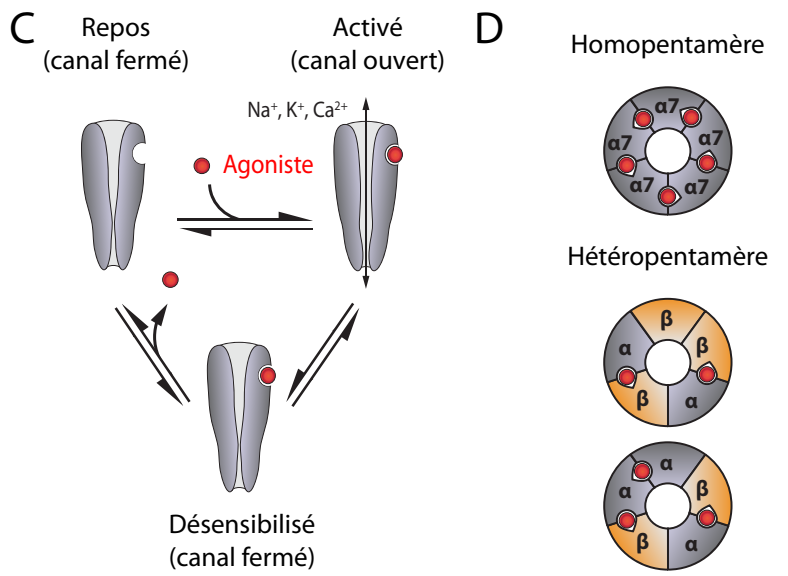

$\mathrm{E}$

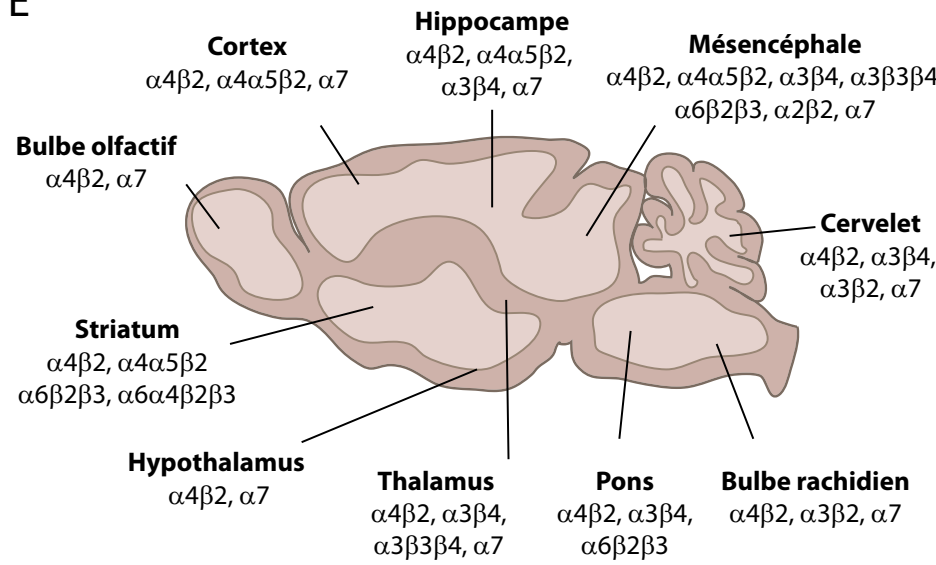

Figure 2. Structure, dynamique et diversité des nAChR neuronaux. (A) Structure tridimensionnelle aux rayons X du récepteur nicotinique $(\alpha 4)_{2}(\beta 2)_{3}$ (PDB ID 5KXI) vue de profil (gauche) et du dessus (droite). Le ligand, ici la nicotine (rouge), se lie à l'interface de la sous-unité principale $\alpha 4$ (grise) et de la sous-unité complémentaire $\beta 2$ (orange) ; (B) Structure tridimensionnelle d'une sous-unité $\alpha 4$. Trois domaines distincts sont présentés: le domaine extracellulaire qui contient le site de liaison de l'agoniste, le domaine transmembranaire (quatre hélices, M1 à M4), et le domaine intracellulaire (boucle M3-M4) dont une partie n'a pas été résolue par cristallographie (pointillés); (C) Représentation schématique des différentes conformations allostériques des nAChR. Il existe trois états à l'équilibre du récepteur: repos, activé (canal ouvert) et désensibilisé; (D) Représentation schématique des différents types d'assemblages des $\mathrm{nAChR}$ : en homopentamère (majoritairement $\alpha 7$ ), constitué de cinq sites agonistes et en hétéropentamère $(\alpha)_{2}(\beta)_{3}$ ou $(\alpha)_{3}(\beta)_{2}$, avec deux ou trois sites agonistes; (E) Répartition des différents sous-types de nAChR dans le cerveau, d'après (Taly et al., 2009).

\section{Diversité structurale et fonctionnelle des récepteurs nicotiniques neuronaux}

Très conservés au cours de l'évolution, les nAChR sont, comme les récepteurs ionotropes à la glycine, au GABA de type $\mathrm{A}\left(\mathrm{GABA}_{\mathrm{A}} \mathrm{R}\right)$ et à la sérotonine $\left(5-\mathrm{HT}_{3}\right)$, des protéines allostériques transmembranaires appartenant à la famille des récepteurs canaux à boucle cystéine (Cys-loop receptors) (Nys et al., 2013). Les nAChR sont composés de cinq sous-unités qui vont s'organiser en rosette (Figure 2A) pour définir un canal perméable aux cations (Morales-Perez et al., 2016). Chaque sous-unité présente quatre segments transmembranaires (M1-M4), avec les segments M2 tapissant la paroi interne du pore (Figure 2B). Les sites de liaison aux agonistes sont situés au niveau du domaine extracellulaire, à l'interface entre deux sous-unités adjacentes (Figure 2A, B). La distance entre le site de liaison et le pore exclut une action directe du ligand sur le canal. L'ouverture de ce dernier est donc soumise à un changement conformationnel du récepteur permettant ainsi le passage des cations selon un gradient électrochimique. Ce type de changement conformationnel a été décrit en 1965 dans le modèle de transitions allostériques de Monod-Wyman-Changeux, par la suite étendu au nAChR (Changeux, 2010a) (Figure 2C). Le récepteur existe en trois états distincts : un état de repos où le canal est fermé, un état actif où le canal est ouvert, et un état désensibilisé dans lequel le canal est fermé malgré la présence de l'agoniste.

Au niveau neuronal, on dénombre neuf sous-unités $\alpha$ et trois sous-unités $\beta$ différentes. Ces sous-unités vont s'assembler en récepteurs canaux homopentamériques $(\alpha 7, \alpha 9)$ ou hétéropentamériques $(\alpha 4 \beta 2, \alpha 3 \beta 4, \alpha 4 \alpha 6 \beta 2$, etc., Figure 2D), offrant ainsi une large palette de combinaisons aux propriétés très diverses (Taly et al., 2009 ; Zoli et al., 2015). De plus, les sous-unités accessoires 
$\alpha 5$ ou $\beta 3$, qui ne participent pas au site de liaison de l'ACh, peuvent s'incorporer dans les récepteurs $\alpha 4 \beta 2$ ou $\alpha 3 \beta 4$. Des études récentes suggèrent l'existence d'hétéropentamères $\alpha 7 \beta 2$ in vivo chez le rongeur (Wu et al., 2016), ce qui rajoute encore à la diversité des $\mathrm{nAChR}$ et à la complexité de la modulation nicotinique dans le cerveau. Les travaux en immunohistochimie, hybridation in situ et marquages par radio-ligands ont permis de décrire la localisation des différentes sous-unités au niveau du SNC. Bien que l'expression des $\mathrm{nAChR}$ soit ubiquitaire (Figure 2E), on retrouve une forte densité au niveau de la rétine, du thalamus, de l'area postrema, de la voie habénulointerpédonculaire (mHb-IPN), de la substance noire ainsi que de l'aire tegmentale ventrale (ATV). Chez les rongeurs, les récepteurs $\alpha 4 \beta 2$ sont les plus abondants au niveau cérébral et présentent une plus grande affinité pour la nicotine. Les sous-unités $\alpha 3$ et $\beta 4$ sont quant à elles fortement co-exprimées, notamment au niveau de la glande pinéale, de la voie habénulo-interpédonculaire, du tractus solitaire, de l'area postrema et de la rétine. Au niveau subcellulaire, on retrouve également une grande diversité de localisation, les nAChR pouvant être retrouvés au niveau pré- ou post-synaptique, axonal, somatique ou encore dendritique.

La combinaison des différentes sous-unités génère une grande variété de types de récepteurs qui ont des propriétés pharmacologiques et électrophysiologiques diverses, rendant leur réponse et leur sensibilité à l'agoniste variables d'une combinaison à une autre. Par exemple, les hétéropentamères $\alpha 4 \beta 2^{*}{ }^{*}$ : possédant au moins les sous-unités $\alpha 4$ et $\beta 2$ ) de haute affinité à la nicotine et l'ACh présentent une forte probabilité d'ouverture du canal, tandis que les homopentamères $\alpha 7$, de faible affinité, présentent une faible probabilité d'ouverture du canal, une forte conductance, une importante perméabilité calcique comparativement à sa perméabilité sodique et une vitesse de désensibilisation rapide. Les récepteurs $\alpha 3 \beta 4$ présentent une faible affinité à l'agoniste ainsi qu'une faible vitesse de désensibilisation. Pour une même sous-unité $\alpha$ i donnée, les oligomères

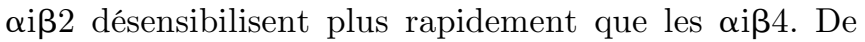
même, les $\alpha 3 \beta j$ sont plus rapidement désensibilisés que les $\alpha 2 \beta \mathrm{j}$ et les $\alpha 4 \beta \mathrm{j}$ (pour revue, voir Le Novère et al., 2002).

\section{Stratégies pharmacologiques et génétiques pour l'étude des nAChR}

Ces différents récepteurs nicotiniques ont été impliqués dans de nombreux comportements tels que le sommeil, la sensation de faim, l'apprentissage, la mémoire, la motivation ou encore la récompense. Ils jouent aussi un rôle important lors des processus de développement, de plasticité et de vieillissement cérébral. Les nAChR jouent bien sûr un rôle crucial dans les différentes étapes de l'addiction à la nicotine. En effet, ces récepteurs sont très exprimés au niveau de l'ATV, structure clé dans le renforcement aux drogues d'abus, ainsi qu'au niveau de la voie habénulo-interpédonculaire qui a récemment été impliquée dans les mécanismes de rechute et dans la mise en place des symptômes du manque lors d'un sevrage nicotinique (Dani \& De Biasi, 2013; Antolin-Fontes et al., 2015). En dehors de ce rôle crucial dans la physiopathologie de l'addiction à la nicotine, une perturbation de la modulation nicotinique a aussi été reliée à la survenue de nombreuses pathologies telles que l'épilepsie, la maladie de Parkinson ou encore la maladie d'Alzheimer (Posadas et al., 2013).

\section{Outils pharmacologiques}

Il existe une large gamme de composés, naturels comme synthétiques, qui agissent sur les nAChR musculaires et neuronaux. Ceux-ci incluent des agonistes entiers et partiels, des antagonistes compétitifs, des bloqueurs du canal, et des modulateurs allostériques positifs ou négatifs (Wonnacott \& Barik, 2007). Étant donné que la séquence protéique est très conservée entre les différentes sous-unités nicotiniques, peu de ces agents pharmacologiques sont sélectifs pour un sous-type particulier. Le récepteur $\alpha 7$ est particulier car il existe de nombreux agents sélectifs pour ce sous-type, notamment les antagonistes compétitifs méthylylcaconitine (MLA) et $\alpha$-bungarotoxine, l'agoniste choline, ou le modulateur allostérique positif PNU 120596. Pour les récepteurs hétéromériques, il existe quelques composés relativement sélectifs, comme la dihydro- $\beta$-érythroïdine (DH $\beta E$, antagoniste $\beta 2 *$ ), la mécamylamine (MEC) ou la 18-méthoxycoronaridine (18-MC, antagoniste sélectif $\alpha 3 \beta 4$ ). Certaines toxines peptidiques naturelles de venin de serpents ou d'escargots marins de la famille des conidae sont très sélectives pour un sous-type, mais ces composés ne traversent pas la barrière hémato-encéphalique, et leur utilisation in vivo n'est théoriquement possible qu'en injection locale. De plus, ces toxines ont en général une très haute affinité pour leur cible, ce qui rend leur effet quasi-irréversible. Un intérêt de la pharmacologie est de pouvoir activer/inhiber de manière aiguë et réversible un (ou plusieurs) sous-types de récepteurs. Par exemple, l'injection systémique de MEC est utilisée pour précipiter les symptômes de manque à la nicotine (Salas et al., 2009). Un autre avantage de la pharmacologie est, en injection locale, d'avoir une précision anatomique. L'injection de 18-MC dans la mHb et l'IPN, par exemple, semble moduler l'auto-administration de nicotine (Glick et al., 2011 ; Jackson et al., 2013) ainsi que la libération de dopamine dans le noyau accumbens après application aiguë de nicotine (McCallum et al., 2012), indiquant le rôle important de ces deux voies neuronales dans l'addiction à la nicotine.

\section{Délétion de gène}

Les souris knock-out pour les différentes sous-unités ont permis de belles avancées dans la compréhension des circuits nicotiniques (Changeux, 2010b ; Drenan \& Lester, 2012). L'utilisation d'une lignée de souris knock-out pour 
la sous-unité $\beta 2\left(\beta 2^{-/-}\right)$a notamment permis de mettre en évidence le rôle de cette sous-unité dans le renforcement à la nicotine (Picciotto et al., 1998) et dans les comportements sociaux (Granon et al., 2003) et locomoteurs (Avale et al., 2008). La sous-unité $\alpha 4$ est souvent associée à la sous-unité $\beta 2$ et de ce fait les souris $\alpha 4^{-/-}$présentent un phénotype assez proche des souris $\beta 2^{-/-}$: le relargage de dopamine et l'augmentation de la locomotion évoqués par la nicotine sont diminués (Marubio et al., 2003) et l'autoadministration de nicotine est abolie chez ces souris (Pons et al., 2008; Exley et al., 2011). Les souris $\alpha 6^{-/-}$ présentent un relargage réduit de dopamine dans le striatum consécutivement à l'administration de nicotine (Champtiaux et al., 2002) et l'auto-administration intraveineuse de nicotine est abolie (Pons et al., 2008). Les souris $\beta 4^{-/-}$sont moins anxieuses (Salas et al., 2003) et présentent moins de symptômes de manque lors d'un sevrage nicotinique (Salas et al., 2004). Les souris $\alpha 3^{-/-}$ quant à elles meurent prématurément (Xu et al., 1999). Les souris $\alpha 7^{-/}$présentent des phénotypes subtils, avec notamment des déficits attentionnels (Young et al., 2004), et pas d'altération de l'effet renforçant de la nicotine (Naylor et al., 2005; Walters et al., 2006). La sous-unité $\alpha 5$ ne participe pas directement à la liaison de la nicotine, néanmoins les souris invalidées pour ce gène sont moins sensibles à la nicotine: elles s'auto-administrent à des doses plus élevées et consomment de plus fortes doses (Fowler et al., 2011; Morel et al., 2013) et ne présentent pas les symptômes somatiques du manque à la nicotine (Salas et al., 2009).

\section{Gain de fonction}

L'invalidation d'une sous-unité nicotinique permet de montrer que cette sous-unité est nécessaire à une fonction physiologique. Cependant, elle ne permet pas de montrer que cette sous-unité est suffisante à la fonction. De plus, la délétion d'un gène peut s'accompagner de compensations développementales. Afin de pallier ces limites, une approche pharmacogénétique a été développée, avec la création de lignées de souris exprimant des nAChR mutants hypersensibles (pour revue voir Drenan \& Lester, 2012). Les mutations ponctuelles mises en jeu concernent un résidu leucine très conservé en position 9' du segment transmembranaire $\mathrm{M} 2$, et ont le plus souvent pour conséquence une augmentation de la sensibilité des nAChR aux agonistes. De faibles concentrations systémiques de nicotine, normalement «inertes», sont utilisées pour activer sélectivement ces récepteurs mutants, et ainsi délinéer leurs rôles in vivo. Cette stratégie a été appliquée aux sous-unités $\alpha 4, \alpha 6, \alpha 7$ et $\alpha 9$. Les mutations L9' sur $\alpha 4$ ont notamment permis d'impliquer cette sous-unité dans l'anxiété (Labarca et al., 2001) et la sensibilisation et le renforcement à la nicotine (Labarca et al., 2001; Tapper et al., 2004). Une mutation équivalente pour la sous-unité $\alpha 6$ (L9'S) a permis de montrer un rôle de cette sous-unité dans l'hyperactivité locomotrice spontanée et induite par la nicotine (Drenan et al., 2008, 2010). De plus, le relargage de dopamine semble altéré chez ces souris. Une autre approche a consisté à générer une lignée de souris (appelée Tabac) dans laquelle la sous-unité $\beta 4$ est surexprimée dans ses sites endogènes, à savoir principalement l'IPN et la $\mathrm{mHb}$ (Frahm et al., 2011). Les souris Tabac montrent une augmentation des courants nicotiniques dans la $\mathrm{mHb}$, et une aversion à la nicotine, qui semble être médiée par la voie habénulo-interpédonculaire.

\section{Réexpression virale}

Les souris transgéniques présentées ci-dessus ne peuvent cependant pas démontrer dans quelle région du cerveau les sous-unités exercent leurs rôles respectifs. Pour répondre à ses questions, et exclure d'éventuels problèmes développementaux, la technique de réexpression virale a été mise en œuvre. Cette technique consiste à réintroduire localement, à l'aide de vecteurs viraux, chez la souris knock-out, le gène codant pour la sous-unité manquante. La réintroduction de récepteurs $\beta 2^{*}$ localement au niveau de l'ATV a notamment permis de restaurer le profil de décharge des neurones dopaminergiques et l'autoadministration de nicotine (Maskos et al., 2005; Mameli-Engvall et al., 2006; Tolu et al., 2012), ainsi que la balance exploitation/exploration (Naudé et al., 2016). Au niveau du cortex préfrontal, la réintroduction de $\beta 2$ restaure les processus attentionnels (Guillem et al., 2011) et l'exploration de la nouveauté (Bourgeois et al., 2012), qui sont altérés chez les souris knock-out. La réexpression de la sous-unité $\beta 4$ dans l'IPN et la $\mathrm{mHb}$ ont permis de renforcer l'hypothèse d'un rôle de la voie habénulo-interpédonculaire dans le renforcement à la nicotine chez la souris (Harrington et al., 2016). La réexpression sélective d' $\alpha 6$ dans l'ATV permet de restaurer l'auto-administration de nicotine (Pons et al., 2008). En ce qui concerne $\alpha 5$, la réexpression dans la $\mathrm{mHb}$ et l'ATV restaurent respectivement la consommation (Fowler et al., 2011) et le renforcement pour de faibles doses de nicotine (Morel et al., 2013).

Malgré des avancées considérables dans la compréhension de la modulation nicotinique des circuits neuronaux, les modèles génétiques et pharmacologiques évoqués précédemment ne permettent pas de résoudre totalement les rôles des différents $\mathrm{nAChR}$ dans la physiopathologie des circuits où ils sont exprimés. La diversité dans l'assemblage des différentes sous-unités, les modifications de la stœechiométrie des pentamères, la distribution anatomique complexe des différents $\mathrm{nAChR}$ au niveau tissulaire et/ou subcellulaire ainsi que des profils d'expression complexes au cours du développement sont autant de défis que la recherche sur les nAChR impose aujourd'hui. Les outils pharmacologiques, même lorsqu'ils sont très sélectifs pour une isoforme, restent difficiles à utiliser, notamment in vivo en application locale où les concentrations réelles et les pharmacocinétiques sont non contrôlables. Il apparaît donc indispensable de développer de nouveaux outils permettant un contrôle des différents nAChR avec une excellente résolution spatio-temporelle (stimulation optique) et une spécificité pharmacologique. 


\section{Photopharmacologie des récepteurs nicotiniques}

Les outils photopharmacologiques sont des ligands qui sont capables de changer de forme, et donc d'activité biologique, sous l'action de la lumière (Figure 1). Ils incorporent dans leur structure un groupement photoisomérisable, tel l'azobenzène, qui change de configuration en fonction de la longueur d'onde utilisée. L'azobenzène possède de nombreux avantages qui expliquent son succès en photopharmacologie (Mourot et al., 2013) :

- la photo-isomérisation induit un changement profond de la géométrie de la molécule, de plane et étendue (trans) à tridimensionnelle et recourbée (cis, Figure 3A), et une augmentation de sa polarité (de 0 à 3 Debye);

- la photo-isomérisation trans-cis s'effectue classiquement avec des longueurs d'onde dans l'UV proche $(340-390 \mathrm{~nm})$, tandis que la photoisomérisation cistrans s'effectue soit lentement dans le noir (secondesjours), soit rapidement dans le bleu-vert (440-520 nm). Il est à noter que les spectres d'absorption ainsi que les cinétiques de relaxation thermique dans le noir sont modulables, par l'introduction de groupements électroattracteurs ou électro-donneurs sur les cycles aromatiques de l'azobenzène;

- les spectres d'absorption des deux isomères sont très différents (Figure 3B), ce qui permet d'obtenir une photo-conversion quasi-totale en utilisant les longueurs d'onde adéquates. Il est également possible de contrôler le pourcentage de chaque isomère, et donc le degré de photo-contrôle du processus biologique, en utilisant soit des longueurs d'onde intermédiaires, soit des intensités lumineuses différentes;

- l'azobenzène est une molécule de petite taille, facile à modifier chimiquement, et pouvant être relativement aisément incorporée dans un pharmacophore;

- la photo-isomérisation de molécules individuelles d'azobenzène se déroule dans des échelles de temps (picosecondes) bien plus rapides que les processus biologiques à contrôler ;

- l'azobenzène ne photo-blanchit pas, permettant un grand nombre de cycles de photo-isomérisation sans fatigue.

L'ensemble de ces propriétés photochimiques fait de l'azobenzène un candidat idéal pour le contrôle photopharmacologique de protéines natives.

Les nAChR musculaires sont les premiers récepteurs à avoir été contrôlés optiquement à l'aide de photoswitchs, à la fin des années 1960, (pour revues, voir Gurney \& Lester, 1987; Damijonaitis et al., 2016). Plusieurs photoswitchs ont été développés, en couplant des groupements azobenzène à différents agonistes comme la carbamylcholine $(\mathrm{CCh})$, le phényltriméthylammonium (PTA), le tétraméthylammonium (TMA) ou la choline (Ch) (Figure $3 \mathrm{C}-\mathrm{D})$. L'azo-CCh et l'azo-PTA se sont en fait révélés être des antagonistes photosensibles plutôt que des agonistes (Deal et al., 1969). Ces composés peuvent inhiber, de manière photo-réversible, la dépolarisation induite par la CCh sur l'électroplaque de l'anguille électrique, en agissant sur les nAChR de type musculaire. Pour les deux photoswitchs, l'inhibition est plus forte dans le noir ou sous lumière visible, quand les azobenzènes sont en trans, que sous illumination UV (320 nm), lorsqu'ils sont en cis: il s'agit donc de trans-antagonistes (Figure 3E). L'introduction du groupement azobenzène semble cependant convertir les agonistes $\mathrm{CCh}$ et PTA en antagonistes. Le mécanisme d'activation des nAChR passe par une constriction des sites ACh (Nemecz et al., 2016); il est probable que le groupement azobenzène, de par son encombrement stérique, empêche les réorganisations structurales menant à l'ouverture du canal. Il a par ailleurs été montré que l'azoCCh bloque aussi, de manière non compétitive, le pore du nAChR musculaire de façon photo-réversible, avec un meilleur blocage pour l'isomère cis (Lester et al., 1979). Ce photoswitch a permis pour la première fois de démontrer, au niveau moléculaire, l'existence d'un mécanisme de bloqueur de canal ouvert. D'autres antagonistes photoisomérisables ont par la suite été utilisés pour mesurer directement, par photo-isomérisation flash, les cinétiques de dissociation du récepteur (Krouse et al., 1985).

Le premier agoniste photochromique des nAChR musculaires à avoir été développé est le BisQ (voir structure Figure 3D) (Bartels et al., 1971). Ce photoswitch possède deux ammoniums quaternaires et ressemble structurellement au décaméthonium (Figure 3C), où la chaîne hydrocarbonée aurait été substituée par un groupement azobenzène. La photo-isomérisation permet de changer drastiquement la distance entre les deux ammoniums quaternaires, ce qui induit un changement tout aussi drastique d'activité biologique. Le trans BisQ est un agoniste puissant et sélectif : 500 fois plus puissant que la $\mathrm{CCh}$ et 50 fois plus puissant que l'ACh pour dépolariser l'électroplaque d'anguille électrique. Son efficacité est en revanche plus faible, similaire au décaméthonium, qui est un agoniste partiel du nAChR musculaire. L'isomère cis est quant à lui quasiment inactif $(<1 \%)$. Le BisQ est donc un trans agoniste (Figure 3E) (Wassermann et al., 1979) qui a été utilisé pour photocontrôler directement et réversiblement le potentiel de membrane de l'électroplaque. Les propriétés photochimiques et structurellement contraintes du BisQ ont également été mises à profit pour définir la topologie des sites agonistes du nAChR musculaire (Wassermann \& Erlanger, 1981), et notamment montrer le caractère hydrophobe de ce site (Wassermann et al., 1979). Des expériences de photoisomérisation flash du BisQ ont permis de faire un saut de concentration ultra-rapide en agoniste (ordre de la $\mu \mathrm{s}$ ) (Nass et al., 1978; Chabala et al., 1986), et de confirmer que le nAChR musculaire a besoin de deux molécules d'agonistes pour s'activer (Sheridan \& Lester, 1982).

Le BisQ est cependant, comme le décaméthonium, sélectif des $n A C h R$ musculaires et ne permet pas de photo-sensibiliser les récepteurs neuronaux (Damijonaitis et al., 2015). Afin de photo-sensibiliser les nAChR neuronaux $\alpha 7$, l'équipe de Dirk Trauner a récemment développé l'Azo-Ch (structure Figure 3D), un dérivé photo-isomérisable de la choline 
A

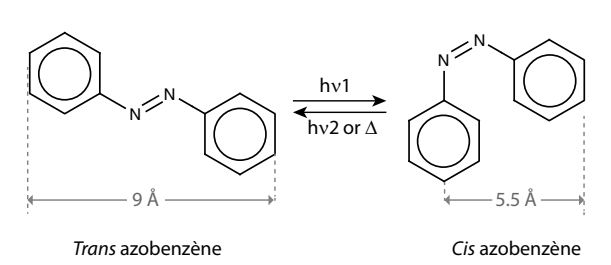

$\mathrm{B}$

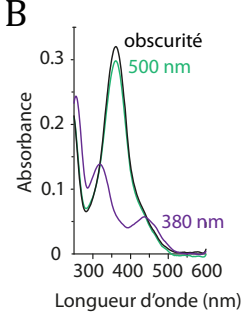

C

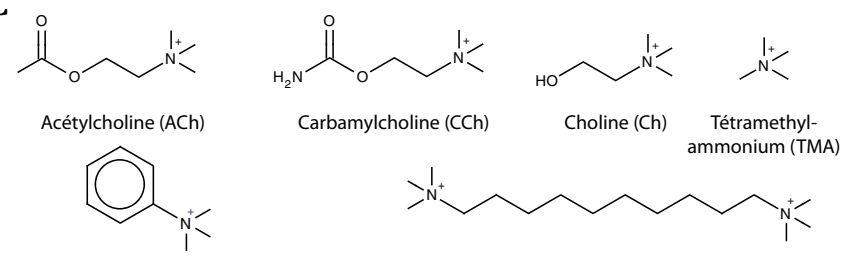

Phenyltrimethylammonium (PTA)

Décaméthonium<smiles>CN(C)CCOC(=O)Nc1ccc(N=Nc2ccc(Br)cc2)cc1</smiles><smiles>CN(C)c1ccc(/N=N/c2ccccc2)cc1</smiles><smiles>CN(C)Cc1cccc(N=Nc2cccc(CN(C)C)c2)c1</smiles>

Bis-Q

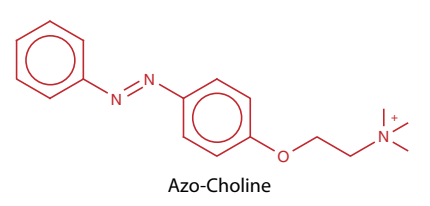

E
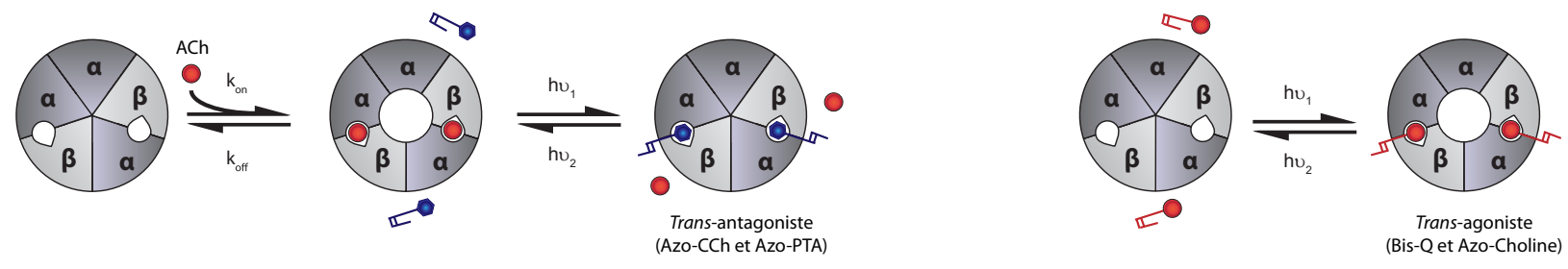

Figure 3. Photo-pharmacologie des nAChR. (A) Structures chimiques des azobenzènes trans et cis. L'isomère trans est thermodynamiquement plus stable que le cis et prédomine dans l'obscurité. Une illumination avec une longueur d'onde courte ( $\mathrm{h} v 1$, classiquement dans l'UV proche 340-390 nm) photo-isomérise l'azobenzène en forme cis. L'isomère cis se relaxe en trans soit spontanément dans le noir ( $\Delta$, s-jours), soit rapidement (ms) sous l'action d'une longueur d'onde plus grande (hv2, classiquement dans le bleu ou le vert 440-520 nm); (B) Spectres d'absorption UV-visible dans un tampon PBS du MAHoCh, un ligand photoisomérisable des nAChR (voir structure Figure 4) dans l'obscurité (trans), sous lumière verte $500 \mathrm{~nm}$ (principalement trans) et sous lumière UV $380 \mathrm{~nm}$ (principalement cis) (d'après Tochitsky et al., 2012); (C) Structures chimiques de différents agonistes des nAChR. L'acétylcholine ( $\mathrm{ACh}$ ) et la carbamylcholine (CCh) sont des agonistes entiers non sélectifs. La choline $(\mathrm{Ch})$ est un agoniste entier sélectif des nAChR $\alpha$ 7. Les tétraméthylammonium (TMA), phényltriméthylammonium (PTA) et décaméthonium sont des agonistes partiels, sélectifs des nAChR musculaires; (D) Structures chimiques de quatre ligands photochromiques des nAChR (isomères trans). L'azo-CCh et l'azo-PTA (en bleu) sont des antagonistes des nAChR musculaires. Le Bis-Q (rouge) est un agoniste partiel sélectif des nAChR musculaires. L'azocholine (rouge) est un agoniste entier sélectif des nAChR $\alpha 7$; (E) Schématisation d'un trans antagoniste (gauche, bleu) et d'un trans agoniste (droite, rouge) pour les nAChR. Le trans antagoniste inhibe la liaison de l'agoniste (rouge), et donc l'activation du récepteur, sous forme trans mais pas cis. Le trans agoniste se lie au récepteur et l'active sous forme trans, mais pas cis.

(Damijonaitis et al., 2015). L'Azo-Ch est un agoniste puissant des $\mathrm{nAChR} \alpha 7$ sous forme trans $(440 \mathrm{~nm})$, mais pas cis $(360 \mathrm{~nm})($ Figure $3 \mathrm{E})$. Ce photoswitch a été utilisé in vitro pour dépolariser des neurones sensoriels de ganglions de la racine dorsale de rats où ces récepteurs sont exprimés, mais aussi exvivo sur des tranches d'hippocampe de souris afin de moduler optiquement la décharge neuronale, et enfin in vivo pour contrôler le comportement de nage chez Conorhabditis elegans.

\section{Pharmacologie optogénétique des récepteurs nicotiniques}

La pharmacologie optogénétique (Figure 1) combine la précision spatio-temporelle du contrôle optique et la spécificité du ciblage génétique (Kramer et al., 2013). Le ciblage pharmacologique provient de l'ancrage covalent d'un photoswitch sur un récepteur génétiquement modifié.
Le point d'ancrage est incorporé à la surface du récepteur via une mutation ponctuelle en cystéine. La cystéine est un acide aminé de choix, car elle possède une fonction thiol nucléophile, qui va pouvoir réagir rapidement (quelques minutes), efficacement et très sélectivement avec des fonctions électrophiles de type maléimide. De plus, l'introduction d'une seule mutation cystéine ne perturbe généralement la fonction de la protéine cible que de manière minimale, voire inexistante. Enfin, bien que le maléimide puisse marquer d'autres protéines de surface ayant des cystéines accessibles, le photo-contrôle demeure spécifique de la protéine mutante, sans effet hors cible, et ceci pour deux raisons : premièrement, les cystéines libres sont peu nombreuses à la surface des cellules, mais surtout, la spécificité d'action de la lumière provient de l'ancrage du photoswitch à une distance extrêmement précise du site pharmacologique. Il est donc fort peu probable qu'une protéine non cible soit, après conjugaison avec le photo- 
switch, rendue photosensible. Afin de trouver le point d'attache idéal, il est nécessaire de scanner la surface du récepteur à proximité du site de liaison, en mutant les acides aminés un à un en cystéine, et cette étape est grandement facilitée par la modélisation moléculaire (Lemoine et al., 2016). Il n'existe en général qu'un nombre très limité de mutations cystéine qui permettent de photosensibiliser un récepteur, démontrant une nouvelle fois la spécificité de la méthode.

Le nAChR a de nouveau été le premier récepteur sur lequel a été greffé de manière covalente un ligand photochromique attachable (LPA), et ce bien avant que la biologie moléculaire ne permette d'incorporer des résidus cystéine par mutagénèse dirigée (Bartels et al., 1971). Dans ce travail fondateur, les auteurs ont utilisé le photoswitch réactif aux cystéines QBr (Figure 4A), dérivé de l'agoniste photosensible BisQ (Figure 3D), et ont pris avantage de la présence fortuite dans le site ACh d'une paire de cystéines vicinales (Figure 4B). Ces cystéines sont naturellement engagées dans un pont disulfure, mais peuvent être réduites sélectivement par une faible concentration de dithiothréitol (DTT) afin d'être marquées par des agonistes covalents (Silman \& Karlin, 1969). Comme pour le BisQ, QBr est un agoniste du nAChR musculaire et sa forme active après attachement covalent est l'isomère trans (Lester et al., 1980). Ce photoswitch attaché a permis de montrer que les cinétiques d'ouverture du canal sont dominées par des transitions intramoléculaires, et semble suggérer, contrairement à ce qui était attendu, qu'une seule molécule d'agoniste pourrait ouvrir le canal, et ce de manière furtive (Lester et al., 1980 ; Chabala \& Lester, 1986). Les cystéines vicinales sont cependant présentes sur toutes les sous-unités $\alpha$ des nAChR, ce qui ne permet pas l'attachement sélectif de $\mathrm{QBr}$ sur un sous-type de nAChR particulier. De plus, l'utilisation nécessaire d'un agent réducteur comme le DTT proscrit l'utilisation de QBr pour des approches physiologiques in vivo.

Avec l'avènement de la biologie moléculaire et de la biologie structurale, il est maintenant possible d'incorporer une mutation cystéine à une position désirée sur un récepteur, afin d'y attacher de manière sélective un LPA. Les premières structures atomiques des sites $\mathrm{ACh}$ du nAChR sont parvenues d'études cristallographiques de l'acetylcholine binding protein (AChBP) (Brejc et al., 2001; Celie et al., 2004), une protéine soluble homologue au domaine extracellulaire des nAChR. La structure de l'AChBP en complexe avec la CCh (Celie et al., 2004) a notamment permis de concevoir rationnellement les premiers nAChR neuronaux photo-contrôlables (LinAChR) (Tochitsky et al., 2012). La première structure tridimensionnelle du récepteur entier n'est devenue disponible que très récemment (Morales-Perez et al., 2016). Deux types de LPA ont été conçus pour le photocontrôle spécifique de $\mathrm{nAChR}$ neuronaux: un agoniste (maléimide azobenzène acétylcholine, ou MAACh) et un antagoniste (maléimide azobenzène homocholine, ou $\mathrm{MAHoCh}$ ), dont les structures chimiques sont inspirées d'un marqueur de photo-affinité agoniste entier des
nAChR musculaires (AC5) (Mourot et al., 2006) et d'un antagoniste compétitif (MG-624) (Gotti et al., 1998), respectivement (structures Figure 4A). Pour le MAACh, un espaceur flexible a été placé entre les groupements ACh et azobenzène, indispensable pour conserver des propriétés agonistes (Mourot et al., 2006; Krieger et al., 2008). Pour le MAHoCh en revanche, l'azobenzène a été placé directement sur le groupement homocholine, afin de créer un encombrement stérique et d'empêcher la constriction du site, et donc l'activation du récepteur (Nemecz et al., 2016). Pour l'attachement covalent du MAACh, sept mutants cystéine ponctuels de la sous-unité $\beta 4$, qui correspond à la partie complémentaire du site $\mathrm{ACh}$, ont été générés. La position de ces cystéines a été choisie selon les résultats du docking virtuel de trans et cis MAACh dans le site ACh. Le but était d'obtenir un récepteur qui soit inerte dans le noir, et activable sous lumière violette, quand le MAACh est en cis. Le criblage a été réalisé en oocyte de xénope sur le récepteur $\alpha 4 \beta 4$ qui désensibilise très peu. Sur les sept mutants cystéine, trois peuvent être activés par la lumière violette et désactivés par la lumière verte (E61C, R113C et S117C, Figure 4B) après marquage avec le MAACh. Ces trois résidus sont équidistants du site agoniste $(10,5-12 \AA)$. La Figure 4C montre l'effet de la lumière sur le MAACh attaché à la cystéine en position 61 , et qui positionne son groupement ACh dans le site agoniste uniquement en configuration cis. Les mutants $\beta 4$ cystéines peuvent être exprimés avec $\alpha 3$ pour produire des récepteurs $\alpha 3 \beta 4$ photo-activables. De plus, les mutations ont pu être transposées facilement sur la sous-unité $\beta 2$, qui est très homologue à $\beta 4$, pour produire des LinAChR $\alpha 4 \beta 2$ photo-activables. L'amplitude des courants induits par la lumière n'est que d'environ $7-17 \%$ des courants induits par l'ACh saturante, car le MAACh est en fait un agoniste partiel des récepteurs hétéromériques neuronaux (A. Mourot, non publié). Le mutant E61C peut également servir de point d'ancrage pour l'antagoniste photoisomérisable $\mathrm{MAHoCh}$, pour produire des récepteurs $\alpha 3 \beta 4$ et $\alpha 4 \beta 2$ photo-inhibables. Le courant induit par l'ACh est alors inhibé sous lumière violette, mais inchangé sous lumière verte ou dans le noir. Les mutants $\beta 4$ et $\beta 2$ E61C permettent donc un contrôle bi-directionnel (photoactivation et -inhibition) des récepteurs hétéromériques neuronaux, après marquage avec MAACh ou MAHoCh, respectivement. De manière importante, que le récepteur soit marqué par MAACh ou MAHoCh, il reste activable par l'ACh dans le noir ou sous lumière verte (photoswitch en trans), avec des EC50 proches de celles du type sauvage, mais devient photo-contrôlable sous lumière violette (cis).

\section{Perspectives}

Au niveau neuronal, l'acétylcholine active les nAChR et agit plus à la manière d'un neuromodulateur que d'un neurotransmetteur synaptique: elle altère l'excitabilité neuronale, influence le relargage de neurotransmetteurs, induit de la plasticité synaptique, coordonne la décharge neuronale de par sa transmission volumique, et donc modifie l'état global de réseaux de neurones (Picciotto 
A<smiles></smiles>

B

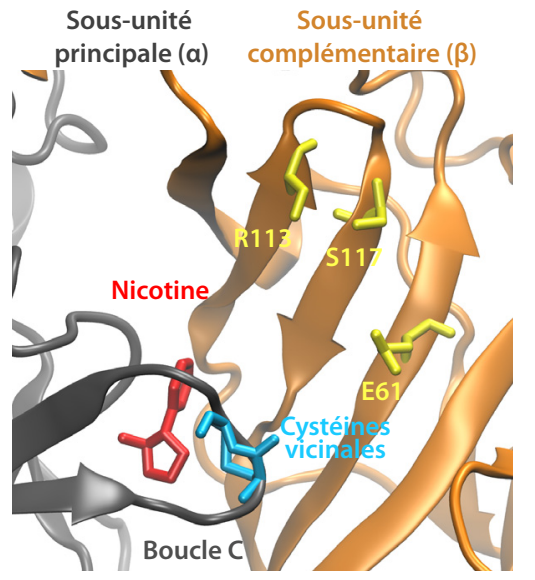

C

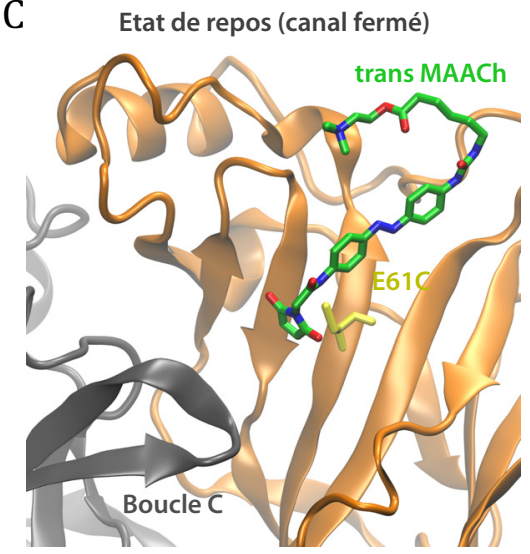

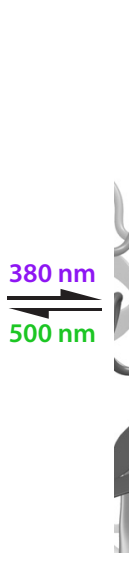

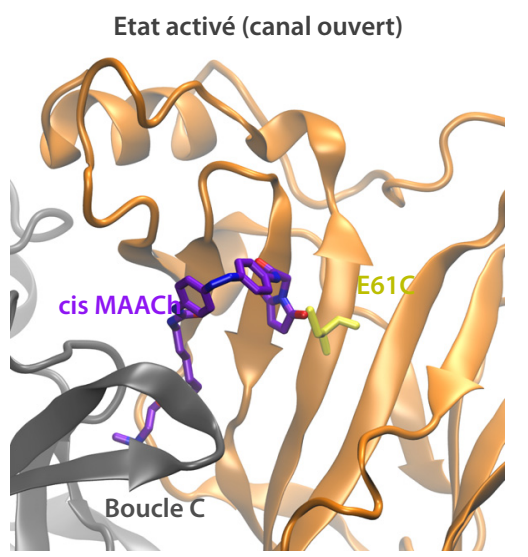

$\mathrm{D}$
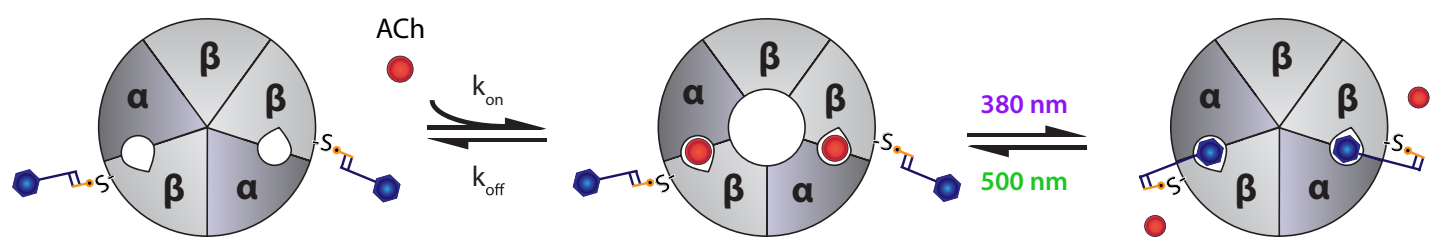

Cis-antagoniste (MAHoCh)
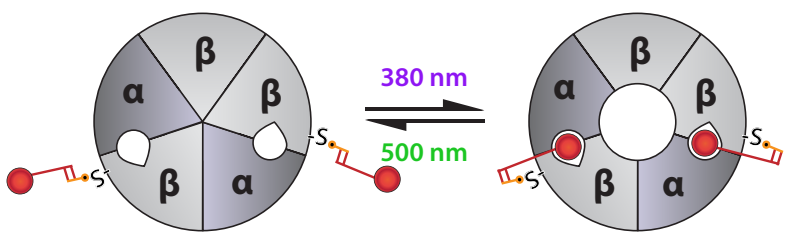

E
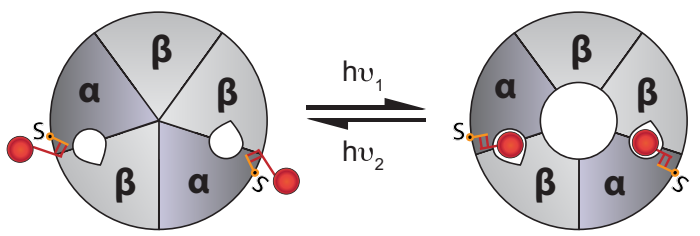

Trans-agoniste (Q-Br)

Figure 4. Pharmacologie optogénétique des nAChR. (A) Structures chimiques de ligands photochromiques attachables (LPA) et de ligands ayant servi à leur design. Le QBr est un agoniste photo-isomérisable utilisé sur le nAChR musculaire, structurellement analogue au BisQ (Figure 3D). Il possède une fonction bromoacétyl (orange) qui est réactive aux thiols. L'AC5 est un marqueur de photoaffinité aux propriétés agonistes ayant servi au design de MAACh, agoniste photo-isomérisable attachable. Le MG-624 est un antagoniste ayant servi au design du MAHoCh, antagoniste photo-isomérisable attachable. MAACh et MAHoCh possèdent tous les deux un groupement maléimide (orange) qui est réactif aux thiols ; (B) Structure tridimensionnelle du site agoniste du nAChR $\alpha 4 \beta 2$ (PDB ID : 5KXI) en complexe avec une molécule de nicotine (rouge). Le site agoniste est à l'interface entre la sous-unité principale $\alpha$ (grise) et la sous-unité complémentaire $\beta$ (orange). Les cystéines vicinales (voisines) (bleu) sur la boucle C sont conservées sur toutes les sous-unités $\alpha$ du nAChR et sont engagées dans un pont disulfure. Ce pont peut être réduit par le DTT pour permettre l'ancrage covalent du QBr et la photo-activation du nAChR musculaire de type sauvage. La mutation ponctuelle des résidus E61, S113 ou R117 (jaune) en cystéine sur la sous-unité $\beta 2$ ou $\beta 4$ permet l'ancrage covalent du MAACh et la photo-activation des nAChR mutés. Seul le mutant E61C permet l'ancrage du MAHoCH et la photo-inhibition du nAChR. (C) Après attachement covalent sur le mutant E61C, le MAACh en configuration trans (dans le noir ou sous lumière verte) est dans l'impossibilité de positionner son groupement ACh dans le site agoniste, derrière la boucle C. Le récepteur reste donc fermé, mais fonctionnel, l'ACh pouvant s'y lier pour l'activer. Sous lumière 
et al., 2012). Les neurones cholinergiques projettent de manière très diffuse sur l'ensemble du SNC, et activent de nombreux nAChR différents, ce qui rend l'étude de ce système complexe. Pouvoir manipuler la neuromodulation nicotinique in vivo, avec une précision spatio-temporelle et possiblement pharmacologique, permettrait de réelles avancées dans la compréhension de ce système. La mise en œuvre in vivo chez le rongeur des outils photochimiques présentés ici nécessite cependant de surmonter les quelques défis suivants.

\section{Améliorer les propriétés pharmacologiques des photoswitchs}

Les photoswitchs diffusibles des $\mathrm{nAChRs}$ sont tous actifs sous forme trans et inactifs sous forme cis. Étant donné que l'isomère trans prédomine dans le noir, il est nécessaire d'illuminer la préparation biologique avec la lumière UV proche si l'on veut que le composé soit inactif, ce qui engendre certaines contraintes expérimentales. Il est donc crucial de développer des agonistes et antagonistes, notamment pour les nAChR neuronaux hétéromériques, qui soient actifs sous forme cis, et donc inactifs dans le noir. Par ailleurs, il est crucial que la différence d'activité entre les deux isomères soit drastique, afin d'avoir un contrôle on/off maximal du processus biologique concerné. Ces deux conditions ont récemment été réunies, pour un inhibiteur «photoswitchable» de la dynamique des microtubules, qui est inactif en trans (dans le noir), et qui possède une différence d'activité de 250 fois entre les deux isomères (Borowiak et al., 2015).

\section{Délivrer la lumière}

La plupart des photoswitchs présentés dans cette revue ont besoin de lumière dans l'UV proche (340-390 nm) pour s'isomériser en cis. Ces longueurs d'onde pénètrent peu dans les tissus, et peuvent potentiellement être cytotoxiques. Il est cependant relativement facile de déplacer vers le rouge les spectres d'absorption de l'azobenzène, en ajoutant des groupements électro-attracteurs ou électrodonneurs sur les cycles aromatiques (Mourot et al., 2011, 2017 ; Kienzler et al., 2013; Rullo et al., 2014 ; Dong et al., 2015). Certains de ces dérivés possèdent même un coefficient d'absorption 2-photons à $850 \mathrm{~nm}$ suffisant pour l'activation 2-photons profonde dans les tissus (Carroll et al., 2015). Les intensités lumineuses nécessaires pour photo-isomériser les groupements azobenzènes sont du même ordre de grandeur que celles utilisées pour les opsines microbiennes. Les technologies optiques (fibres optiques, LED, etc...) développées pour l'optogénétique classique (Deisseroth, 2015) sont donc utilisables pour la photochimie invivo. De plus, de nouvelles méthodes optiques, telle l'holographie digitale (Vaziri \& Emiliani, 2012), permettent de sculpter en trois dimensions une zone de photo-stimulation, ou même de photo-stimuler en parallèle plusieurs zones, ajoutant une nouvelle dimension à la précision spatiale qu'offre la lumière.

\section{Délivrer le photoswitch}

Les photoswitchs sont de petites molécules solubles qui diffusent généralement bien dans les tissus. Ils doivent cependant être délivrés localement, notamment s'ils contiennent un groupement réactif aux cystéines comme le maléimide. Une simple application locale suffit pour les régions superficielles telles le cortex (Lin et al., 2015) ou la cornée (Mourot et al., 2012). Les photoswitchs peuvent également être injectés localement dans l'œil à l'aide d'une seringue (Tochitsky et al., 2014) ou dans des régions profondes du cerveau à l'aide d'une canule et d'un appareil stéréotaxique (Durand-de Cuttoli, Mondoloni et Mourot, non publié). De nouveaux systèmes opto-fluidiques programmables sans fil ont été développés, permettant de délivrer localement une drogue et la lumière grâce à des LED miniatures, et pourraient faciliter l'utilisation d'agents photochimiques in vivo (Jeong et al., 2015).

\section{Délivrer le gène}

Pour la pharmacologie optogénétique, le gène codant pour le mutant cystéine doit être également délivré dans le système nerveux. Le gène peut être surexprimé localement à l'aide de virus, mais la surexpression peut potentiellement conduire à un niveau non physiologique d'expression du transgène. Dans le cas du $\mathrm{nAChR}$ ou du récepteur $\mathrm{GABA}_{\mathrm{A}}$, qui sont tous les deux des récepteurs canaux pentamériques, le mutant cystéine doit s'assembler avec d'autres sous-unités endogènes, qui vraisemblablement vont réguler les niveaux d'expression du récepteur à la surface (Lin et al., 2015). Une alternative, certes plus coûteuse en temps et argent, est de développer une souris

violette, le MAACh passe en configuration cis recourbée, et son groupement ACh peut atteindre le site agoniste et photo-activer le récepteur. Le retour à l'état fermé se fait rapidement sous lumière verte, ou lentement à l'obscurité ; (D) Photo-régulation de l'activité des LinAChR par un LPA cis antagoniste (haut, MAHoCh) et d'un LPA cis agoniste (bas, MAACh). L'introduction d'une cystéine proche du site de liaison du ligand sur la sous-unité $\beta$ sert de point d'ancrage au LPA. Le MAHoCh et le MAACh possèdent un groupement cystéine-réactif, le maléimide, qui permet d'attacher de manière covalente le LPA sur le récepteur, et ainsi de rendre le nAChR photosensible. En configuration trans, dans le vert ou à l'obscurité, le récepteur conserve son activité endogène, puisque le ligand du LPA est éloigné du site de liaison du ligand, ne modifiant pas l'activité naturelle du récepteur. Un flash de lumière violette est suffisant pour que LPA passe d'une configuration trans à cis, permettant d'amener le ligand dans son site de liaison, et donc de photoinhiber le récepteur (haut, MAHoCh) ou de photo-activer le récepteur (bas, MAACh); (E) Photo-activation des nAChR par un LPA trans agoniste $(\mathrm{QBr})$. Le QBr possède un groupement cytéine-réactif qui permet la liaison covalente du LPA sur les cystéines vicinales (réduites) des sous-unités $\alpha$. Le passage d'une configuration cis à trans permet d'amener le ligand dans son site de liaison et de photoactiver le récepteur musculaire. 
transgénique qui porte naturellement la mutation cystéine et respecte les sites et niveaux d'expression endogènes du récepteur. La transduction virale a néanmoins l'avantage de pouvoir cibler l'expression du transgène sur un type cellulaire donné, en utilisant, par exemple, le système CreLox (Deisseroth, 2015), ou dans une région anatomiquement définie, et ainsi de pouvoir étudier distinctement les rôles pré- $v s$ post-synaptiques d'un sous-type de récepteur dans la transmission neuronale.

\section{Marquage covalent}

Pour la pharmacologie optogénétique encore, le photoswitch doit s'ancrer de manière covalente sur le mutant cystéine. Cette cystéine doit donc être disponible et non oxydée. Un agent réducteur tel le TCEP peut être utilisé (Lin et al., 2015) mais, selon notre expérience, n'est pas indispensable (Durand-de Cuttoli, Mondoloni et Mourot, non publié). Il existe également d'autres alternatives au marquage maléimide-cystéine. Le photoswitch peut, par exemple, être conjugué à un SNAP tag (Broichhagen et al., 2015). Le $S N A P$ tag est un domaine catalytique, plus volumineux que la substitution cystéine $(19,4 \mathrm{kDa})$, mais pouvant être fusionné à n'importe quelle protéine d'intérêt, ou incorporé à la surface de cellules ciblées génétiquement (Shields et al., 2017), et permettant un marquage covalent extrêmement spécifique et efficace. Une autre alternative est de photo-sensibiliser les récepteurs de manière totalement génétique, sans recourir à la chimie. Il existe, par exemple, des domaines de protéines de plante, tels les domaines LOV, qui sont naturellement photosensibles et peuvent être fusionnés à des protéines pour les rendre photo-contrôlables (pour revue, voir Zhou et al., 2015). Les cinétiques de photoisomérisation des domaines LOV sont néanmoins bien inférieures à celles des azobenzènes. Enfin, la technique d'incorporation d'acides aminés non naturels permet de photo-sensibiliser récepteurs et canaux, et cette technologie a récemment été mise en œuvre chez la souris in vivo, ouvrant de nouvelles possibilités dans la photo-régulation de protéines endogènes (Kang et al., 2013).

Les techniques optiques, optogénétiques et chémogénétiques, permettant de contrôler de manière aiguë, réversible et ciblée l'activité de protéines endogènes continuent de croître et de se diversifier. Ces techniques vont indubitablement changer la façon dont on manipule et étudie le système nerveux au niveau moléculaire, et nous éclairer sur les différentes fonctions des récepteurs et canaux membranaires.

Remerciements. Ce travail a été soutenu par l'ANR-JCJC Nicopto, un financement NARSAD Young Investigator de la fondation Brain $\&$ Behavior Research, et la fondation Medisite. RDC a reçu une bourse de thèse du DIM Cerveau \& Pensée, programme de la région Ile-de-France, et une bourse de quatrième année de thèse de la FRM (FDT20170437427). Le laboratoire fait partie du réseau de l'école des neurosciences de
Paris Ile-de-France RTRA et du LABEX BIO-PSY. Nous remercions Philippe Faure (NPS-IBPS) pour la relecture du manuscrit.

\section{Références}

Antolin-Fontes, B., Ables, J.L., Görlich, A., Ibañez-Tallon, I. (2015). The habenulo-interpeduncular pathway in nicotine aversion and withdrawal. Neuropharmacology, 96, 213-222.

Avale, M.E.M., Faure, P., Pons, S., Robledo, P.P., Deltheil, T. T., David, D.J.D., Gardier, A.M.A., Maldonado, R.R., Granon, S.S., Changeux, J.-P., Maskos, U. (2008). Interplay of beta2* nicotinic receptors and dopamine pathways in the control of spontaneous locomotion. Proc Nat Acad Sci USA, 105, 15991-15996.

Banghart, M.R., Borges, K., Isacoff, E.Y., Trauner, D., Kramer, R.H. (2004). Light-activated ion channels for remote control of neuronal firing. Nat Neurosc, 7, 1381-1386.

Banghart, M.R., Mourot, A., Fortin, D.L., Yao, J.Z., Kramer, R.H., Trauner, D. (2009). Photochromic blockers of voltage-gated potassium channels. Angew Chem Int Ed Engl, 48, 9097-9101.

Barber, D.M., Schönberger, M., Burgstaller, J., Levitz, J., Weaver, C.D., Isacoff, E.Y., Baier, H., Trauner, D. (2016). Optical control of neuronal activity using a light-operated GIRK channel opener (LOGO). Chem Sci, 7, 2347-2352.

Bartels, E., Wassermann, N.H., Erlanger, B.F. (1971). Photochromic activators of the acetylcholine receptor. Proc Nat Acad Sci USA, 68, 1820-1823.

Berlin, S., Isacoff, E.Y. (2017) Synapses in the spotlight with synthetic optogenetics. EMBO Rep, 18, 677-692.

Berlin, S., Szobota, S., Reiner, A., Carroll, E.C., Kienzler, M.A., Guyon, A., Xiao, T., Trauner, D., Isacoff, E.Y. (2016). A family of photoswitchable NMDA receptors. eLife, 5, e12040, 2016 Mar 1, doi: 10.7554/eLife.12040.

Borowiak, M., Nahaboo, W., Reynders, M., Nekolla, K., Jalinot, P., Hasserodt, J., Rehberg, M., Delattre, M., Zahler, S., Vollmar, A., Trauner, D., Thorn-Seshold, O. (2015). Photoswitchable inhibitors of microtubule dynamics optically control mitosis and cell death. Cell, 162, 403-411.

Bourgeois, J.P., Meas-Yeadid, V., Lesourd, A.M., Faure, P., Pons, S., Maskos, U., Changeux, J.-P., Olivo-Marin, J.C., Granon, S. (2012). Modulation of the mouse prefrontal cortex activation by neuronal nicotinic receptors during novelty exploration but not by exploration of a familiar environment. Cereb Cortex, 22, 1007-1015.

Brejc, K., van Dijk, W.J., Klaassen, R.V., Schuurmans, M., van Der Oost, J., Smit, A.B., Sixma, T.K. (2001). Crystal structure of an ACh-binding protein reveals the ligandbinding domain of nicotinic receptors. Nature, 411, 269-276.

Broichhagen, J., Damijonaitis, A., Levitz, J., Sokol, K.R., Leippe, P., Konrad, D., Isacoff, E.Y., Trauner, D. (2015). Orthogonal optical control of a G Protein-coupled receptor with a SNAPtethered photochromic ligand. ACS Cent Sci, 1, 383-393.

Caporale, N., Kolstad, K.D., Lee, T., Tochitsky, I., Dalkara, D., Trauner, D., Kramer, R.H., Dan, Y., Isacoff, E.Y., Flannery, J.G. (2009). LiGluR restores visual responses in rodent models of inherited blindness. Mol Ther, 19, 1212-1219.

Carroll, E.C., Berlin, S., Levitz, J., Kienzler, M.A., Yuan, Z., Madsen, D., Larsen, D.S., Isacoff, E.Y. (2015). Two-photon brightness of azobenzene photoswitches designed for glutamate receptor optogenetics. Proc Nat Acad Sci USA, 112, E776-785

Celie, P.H.N., van Rossum-Fikkert, S.E., van Dijk, W.J., Brejc, K., Smit, A.B., Sixma, T.K. (2004). Nicotine and carbamylcholine binding to nicotinic acetylcholine receptors as studied in AChBP Crystal structures. Neuron, 41, 8-8. 
Chabala, L.D., Lester, H.A. (1986). Activation of Acetylcholine receptor channels by covalently bound agonists in cultured rat myoballs. J Physiol, 379, 83-108.

Chabala, L.D.L., Gurney, A.M., Lester, H.A. (1986). Doseresponse of acetylcholine receptor channels opened by a flashactivated agonist in voltage-clamped rat myoballs. J Physiol, $371,407-433$.

Champtiaux, N., Han, Z.-Y., Bessis, A., Rossi, F.M., Zoli, M., Marubio, L., McIntosh, J.M., Changeux, J.-P. (2002). Distribution and pharmacology of alpha 6-containing nicotinic acetylcholine receptors analyzed with mutant mice. J Neurosci, 22, 1208-1217.

Changeux, J.-P. (2010a). Allosteric receptors: from electric organ to cognition. Ann Rev Pharmacol Toxicol, 50, 1-38.

Changeux, J.-P. (2010b). Nicotine addiction and nicotinic receptors: lessons from genetically modified mice. Nat Rev Neurosci, 11, 1-13.

Damijonaitis, A., Broichhagen, J., Urushima, T., Hüll, K., Nagpal, J., Laprell, L., Schönberger, M., Woodmansee, D.H., Rafiq, A., Sumser, M.P., Kummer, W., Gottschalk, A., Trauner, D. (2015). AzoCholine enables optical control of alpha 7 nicotinic acetylcholine receptors in neural networks. ACS Chem Neurosci, 6, 701-707.

Damijonaitis, A., Barber, D.M., Trauner, D. (2016). The photopharmacology of nicotinic acetylcholine receptors. Neurotransmitter, 3, e1292.

Dani, J.A., De Biasi, M. (2013). Mesolimbic dopamine and habenulo-interpeduncular pathways in nicotine withdrawal. Cold Spring Harb Perspect Med, 3, a012138-8.

Deal, W.J., Erlanger, B.F., Nachmansohn, D.D. (1969). Photoregulation of biological activity by photochromic reagents. 3 . Photoregulation of bioelectricity by acetylcholine receptor inhibitors. Proc Nat Acad Sci USA, 64, 1230-1234.

Deisseroth, K. (2015). Optogenetics: 10 years of microbial opsins in neuroscience. Nat Neurosci, 18, 1213-1225.

Dong, M., Babalhavaeji, A., Samanta, S., Beharry, A.A., Woolley, G.A. (2015). Red-shifting azobenzene photoswitches for in vivo use. Acc Chem Res, 48, 2662-2670.

Drenan, R.M., Lester, H.A. (2012). Insights into the neurobiology of the nicotinic cholinergic system and nicotine addiction from mice expressing nicotinic receptors harboring gain-offunction mutations. Pharmacol Rev, 64, 869-879.

Drenan, R.M., Grady, S.R., Whiteaker, P., McClure-Begley, T. McKinney, S., Miwa, J.M., Bupp, S., Heintz, N., McIntosh, J. M., Bencherif, M., Marks, M.J., Lester, H.A. (2008). In vivo activation of midbrain dopamine neurons via sensitized, high-affinity $\alpha 6$ nicotinic acetylcholine receptors.Neuron, 60 , 123-136.

Drenan, R.M., Grady, S.R., Steele, A.D., McKinney, S., Patzlaff, N.E., McIntosh, J.M., Marks, M.J., Miwa, J.M., Lester, H.A. (2010). Cholinergic modulation of locomotion and striatal dopamine release is mediated by $\alpha 6 \alpha 4^{*}$ nicotinic acetylcholine receptors. J Neurosci, 30, 9877-9889.

Ellis-Davies, G.C.R. (2007). Caged compounds: photorelease technology for control of cellular chemistry and physiology. Nat Methods, 4, 619-628.

Exley, R., Maubourguet, N., David, V., Eddine, R., Evrard, A., Pons, S., Marti, F., Threlfell, S., Cazala, P., McIntosh, J.M., Changeux, J.-P., Maskos, U., Cragg, S.J., Faure, P. (2011). Distinct contributions of nicotinic acetylcholine receptor subunit alpha4 and subunit alpha6 to the reinforcing effects of nicotine. Proc Nat Acad Sci USA, 108, 75777582 .

Fortin, D.L., Dunn, T.W., Fedorchak, A., Allen, D., Montpetit, R., Banghart, M.R., Trauner, D., Adelman, J.P., Kramer, R. H. (2011). Optogenetic photochemical control of designer $\mathrm{K}^{+}$ channels in mammalian neurons. J Neurophysiol, 106, 488-496.
Fowler, C.D., Lu, Q., Johnson, P.M., Marks, M.J., Kenny, P.J. (2011). Habenular A5 nicotinic receptor subunit signalling controls nicotine intake. Nature, 471, 597-601.

Frahm, S., S limak, M.A., Ferrarese, L., Santos-Torres, J., Antolin-Fontes, B., Auer, S., Filkin, S., Pons, S., Fontaine, J.-F., Tsetlin, V., Maskos, U., Ibañez-Tallon, I. (2011). Aversion to nicotine is regulated by the balanced activity of beta 4 and alpha5 nicotinic receptor subunits in the medial habenula. Neuron, 70, 522-535.

Frank, J.A., Moroni, M., Moshourab, R., Sumser, M., Lewin, G. R., Trauner, D. (2015). Photoswitchable fatty acids enable optical control of TRPV1. Nat Commun, 6, 1-11.

Glick, S.D., Sell, E.M., McCallum, S.E., Maisonneuve, I.M. (2011). Brain regions mediating A3 $\beta 4$ nicotinic antagonist effects of 18 -MC on nicotine self-administration. Eur $J$ Pharmacol, 669, 71-75.

Gotti, C., Balestra, B., Moretti, M., Rovati, G.E., Maggi, L., Rossoni, G., Berti, F., Villa, L., Pallavicini, M., Clementi, F. (1998). 4-Oxystilbene compounds are selective ligands for neuronal nicotinic alphabungarotoxin receptors. Brit $J$ Pharmacol, 124, 1197-1206.

Granon, S., Faure, P., Changeux, J.-P. (2003). Executive and social behaviors under nicotinic receptor regulation. Proc Nat Acad Sci USA, 100, 9596-9601.

Guillem, K., Bloem, B., Poorthuis, R.B., Loos, M., Smit, A.B., Maskos, U., Spijker, S., Mansvelder, H.D. (2011). Nicotinic acetylcholine receptor beta2 subunits in the medial prefrontal cortex control attention. Science, 333, 888-891.

Gurney, A.M., Lester, H.A. (1987). Light-flash physiology with synthetic photosensitive compounds. Physiol Rev, 67, 583617.

Harrington, L., Viñals, X., Herrera-Solís, A., Flores, A., Morel, C., Tolu, S., Faure, P., Maldonado, R., Maskos, U., Robledo, P. (2016). Role of $\beta 4^{*}$ nicotinic acetylcholine receptors in the habenulo-interpeduncular pathway in nicotine reinforcement in mice. Neuropsychopharmacology, 41, 1790-1802.

Jackson, K.J., Sanjakdar, S.S., Muldoon, P.P., McIntosh, J.M., Damaj, M.I. (2013). The A3ß4* nicotinic acetylcholine receptor subtype mediates nicotine reward and physical nicotine withdrawal signs independently of the A5 subunit in the mouse. Neuropharmacology, 70, 228-235.

Janovjak, H., Szobota, S., Wyart, C., Trauner, D., Isacoff, E.Y. (2010). A light-gated, potassium-selective glutamate receptor for the optical inhibition of neuronal firing. Nat Neurosci, 13, 1027-1032.

Jeong, J.-W., McCall, J.G., Shin, G., Zhang, Y., Al-Hasani, R., Kim, M., Li, S., Sim, J.Y., Jang, K.-I., Shi, Y., Hong, D.Y., Liu, Y., Schmitz, G.P., Xia, L., He, Z., Gamble, P., Ray, W.Z., Huang, Y., Bruchas, M.R., Rogers, J.A. (2015). Wireless optofluidic systems for programmable in vivo pharmacology and optogenetics. Cell, 162, 662-674.

Kang, J.-Y., Kawaguchi, D., Coin, I., Xiang, Z., O'Leary, D.D. M., Slesinger, P.A., Wang, L. (2013). In vivo expression of a light-activatable potassium channel using unnatural amino acids. Neuron, $80,358-370$

Kienzler, M.A., Reiner, A., Trautman, E., Yoo, S., Trauner, D., Isacoff, E.Y. (2013). A red-shifted, fast-relaxing azobenzene photoswitch for visible light control of an ionotropic glutamate receptor. J Am Chem Soc, 135, 1768317686.

Kim, C.K., Adhikari, A., Deisseroth, K. (2017). Integration of optogenetics with complementary methodologies in systems neuroscience. Nat Rev Neurosci, 18, 222-235.

Kramer, R.H., Mourot, A., Adesnik, H. (2013). Optogenetic pharmacology for control of native neuronal signaling proteins. Nat Neurosci, 16, 816-823. 
Krieger, F., Mourot, A., Araoz, R., Kotzyba-Hibert, F., Molgó, J., Bamberg, E., Goeldner, M. (2008). Fluorescent agonists for the torpedo nicotinic acetylcholine receptor. Chem Bio Chem, 9, 1146-1153.

Krouse, M.E.M., Lester, H.A., Wassermann, N.H., Erlanger, B. F. (1985). Rates and equilibria for a photoisomerizable antagonist at the acetylcholine receptor of electrophorus electroplaques. J Gen Physiol, 86, 235-256.

Labarca, C., Schwarz, J., Deshpande, P., Schwarz, S., Nowak, M. W., Fonck, C., Nashmi, R., Kofuji, P., Dang, H., Shi, W., Fidan, M., Khakh, B.S., Chen, Z., Bowers, B.J., Boulter, J., Wehner, J.M., Lester, H.A. (2001). Point mutant mice with hypersensitive alpha 4 nicotinic receptors show dopaminergic deficits and increased anxiety. Proc Nat Acad Sci USA, 98, $2786-2791$.

Laprell, L., Repak, E., Franckevicius, V., Hartrampf, F., Terhag, J., Hollmann, M., Sumser, M., Rebola, N., DiGregorio, D.A., Trauner, D. (2015). Optical control of NMDA receptors with a diffusible photoswitch. Nat Commun, 6, 1-11.

Le Novère, N., Corringer, P.-J., Changeux, J.-P. (2002). The diversity of subunit composition in nAChRs: evolutionary origins, physiologic and pharmacologic consequences. $J$ Neurobiol, 53, 447-56.

Lemoine, D., Durand-de Cuttoli, R., Mourot, A. (2016). Optogenetic control of mammalian ion channels with chemical photoswitches. Methods Mol Biol, 1408, 177-193.

Lerch, M.M., Hansen, M.J., van Dam, G.M., Szymanski, W., Feringa, B.L. (2016). Emerging targets in photopharmacology. Angew Chem Int Ed Engl, 55, 10978-10999.

Lester, H.A., Krouse, M.E., Nass, M.M., Wassermann, N.H., Erlanger, B.F. (1979). Light-activated drug confirms a mechanism of ion channel blockade. Nature, 280, 509-510.

Lester, H.A., Krouse, M.E.M., Nass, M.M., Wassermann, N.H. Erlanger, B.F. (1980). A covalently bound photoisomerizable agonist: comparison with reversibly bound agonists at electrophorus electroplaques. J GenPhysiol, 75, 207-232.

Levitz, J., Pantoja, C., Gaub, B., Janovjak, H., Reiner, A., Hoagland, A., Schoppik, D., Kane, B., Stawski, P., Schier, A. F., Trauner, D., Isacoff, E.Y. (2013). Optical control of metabotropic glutamate receptors. Nature Neurosci, 16, 507-516.

Levitz, J., Popescu, A.T., Reiner, A., Isacoff, E.Y. (2016). A toolkit for orthogonal and invivo optical manipulation of ionotropic glutamate receptors. Front Mol Neurosci, $9,163$.

Lin, W.-C., Davenport, C.M., Mourot, A., Vytla, D., Smith, C.M., Medeiros, K.A., Chambers, J.J., Kramer, R.H. (2014). Engineering a light-regulated GABAA receptor for optical control of neural inhibition. ACS Chem Biol, 9, 14141419.

Lin, W.-C., Tsai, M.-C., Davenport, C.M., Smith, C.M., Veit, J., Wilson, N.M., Adesnik, H., Kramer, R.H. (2015). A comprehensive optogenetic pharmacology toolkit for in vivo control of GABA(a) receptors and synaptic inhibition. Neuron, 88, 879-891.

Mameli-Engvall, M., Evrard, A., Pons, S., Maskos, U., Svensson, T.H., Changeux, J.-P., Faure, P. (2006). Hierarchical control of dopamine neuron-firing patterns by nicotinic receptors. Neuron, 50, 911-921.

Marubio, L.M., Gardier, A.M., Durier, S., David, D., Klink, R., Arroyo-Jimenez, M.M., McIntosh, J.M., Rossi, F., Champtiaux, N., Zoli, M., Changeux, J.-P. (2003). Effects of nicotine in the dopaminergic system of mice lacking the alpha4 subunit of neuronal nicotinic acetylcholine receptors. Eur J Neurosci, 17, 1329-1337.

Maskos, U., Molles, B.E., Pons, S., Besson, M., Guiard, B.P., Guilloux, J.P., Evrard, A., Cazala, P., Cormier, A., MameliEngvall, M., Dufour, N., Cloëz-Tayarani, I., Bemelmans,
A.P., Mallet, J., Gardier, A.M., David, V., Faure, P., Granon, S., Changeux, J.-P. (2005). Nicotine reinforcement and cognition restored by targeted expression of nicotinic receptors. Nature, 436, 103-107.

McCallum, S.E., Cowe, M.A., Lewis, S.W., Glick, S.D. (2012). A3ß4 Nicotinic acetylcholine receptors in the medial habenula modulate the mesolimbic dopaminergic response to acute nicotine invivo. Neuropharmacology, 63, 434440.

Morales-Perez, C.L., Noviello, C.M., Hibbs, R.E. (2016). X-ray structure of the human A $4 \beta 2$ nicotinic receptor. Nature, 538 , 411-415.

Morel, C., Fattore, L., Pons, S., Hay, Y.A., Marti, F., Lambolez, B., De Biasi, M., Lathrop, M., Fratta, W., Maskos, U., Faure, P. (2013). Nicotine consumption is regulated by a human polymorphismin dopamine neurons. Mol Psychiatry, 19, 930936.

Mourot, A., Rodrigo, J., Kotzyba-Hibert, F., Bertrand, S., Bertrand, D., Goeldner, M. (2006). Probing the reorganization of the nicotinic acetylcholine receptor during desensitization by time-resolved covalent labeling using $[3 \mathrm{H}]$ AC5, a photoactivatable agonist. Mol Pharmacology, 69, $452-461$

Mourot, A., Kienzler, M.A., Banghart, M.R., Fehrentz, T., Huber, F.M.E., Stein, M., Kramer, R.H., Trauner, D. (2011). Tuning photochromic ion channel blockers. ACS Chem Neurosci, 2, 536-543.

Mourot, A., Fehrentz, T., Le Feuvre, Y., Smith, C.M., Herold, C., Dalkara, D., Nagy, F., Trauner, D., Kramer, R.H. (2012). Rapid optical control of nociception with an ion-channel photoswitch. Nat Methods, 9, 396-402.

Mourot, A., Tochitsky, I., Kramer, R.H. (2013). Light at the end of the channel: optical manipulation of intrinsic neuronal excitability with chemical photoswitches. Front Mol Neurosci, 6, 1-15.

Mourot, A., Herold, C., Kienzler, M.A., Kramer, R.H. (2017). Understanding and improving photo-control of ion channels in nociceptors with azobenzene photoswitches. Brit $J$ Pharmacol, doi: 10.1111/bph.13923, sous presse.

Nargeot, J., Lester, H.A., Birdsall, N.J., Stockton, J., Wassermann, N.H., Erlanger, B.F. (1982). A photoisomerizable muscarinic antagonist. Studies of binding and of conductance relaxations in frog heart. J Gen Physiol, 79, 657-678.

Nass, M.M., Lester, H.A., Krouse, M.E. (1978). Response of acetylcholine receptors to photoisomerizations of bound agonist molecules. Biophys J, 24, 135-160.

Naudé, J., Tolu, S., Dongelmans, M., Torquet, N., Valverde, S., Rodriguez, G., Pons, S.E.P., Maskos, U., Mourot, A., Marti, F., Faure, P. (2016). Nicotinic receptors in the ventral tegmental area promote uncertainty-seeking. Nat Neurosci, 19, 471-478.

Naylor, C., Quarta, D., Fernandes, C., Stolerman, I.P. (2005). Tolerance to nicotine in mice lacking alpha7 nicotinic receptors. Psychopharmacology, 180, 558-563.

Nemecz, Á., Prevost, M.S., Menny, A., Corringer, P.-J. (2016). Emerging molecular mechanisms of signal transduction in pentameric ligand-gated ion channels. Neuron, 90, $452-470$.

Nys, M., Kesters, D., Ulens, C. (2013). Structural insights into cys-loop receptor function and ligand recognition. Biochem Pharmacol, 86, 1042-1053.

Picciotto, M.R., Zoli, M., Rimondini, R., Léna, C., Marubio, L.M., Pich, E.M., Fuxe, K., Changeux, J.-P. (1998). Acetylcholine receptors containing the beta2 subunit are involved in the reinforcing properties of nicotine. Nature, 391, 173-177. 
Picciotto, M.R., Higley, M.J., Mineur, Y.S. (2012). Acetylcholine as a neuromodulator: cholinergic signaling shapes nervous system function and behavior. Neuron, 76, 116-129.

Polosukhina, A., Litt, J., Tochitsky, I., Nemargut, J., Sychev, Y., De Kouchkovsky, I., Huang, T., Borges, K., Trauner, D., Van Gelder, R.N., Kramer, R.H. (2012). Photochemical restoration of visual responses in blind mice. Neuron, 75 , 271-82.

Pons, S., Fattore, L., Cossu, G., Tolu, S., Porcu, E., McIntosh, J. M., Changeux, J.-P., Maskos, U., Fratta, W. (2008). Crucial role of alpha4 and alpha 6 nicotinic acetylcholine receptor subunits from ventral tegmental area in systemic nicotine self-administration. J Neurosci, 28, 12318-12327.

Posadas, I., López-Hernández, B., Ceña, V. (2013). Nicotinic receptors in neurodegeneration. Current Neuropharmacol, 11, 298-314.

Quandt, G., Höfner, G., Pabel, J., Dine, J., Eder, M., Wanner, K.T. (2014). First photoswitchable neurotransmitter transporter inhibitor: light-induced control of $\gamma$-aminobutyric acid transporter 1 (GAT1) activity in mouse brain. J Med Chem, $57,6809-6821$.

Rullo, A., Reiner, A., Reiter, A., Trauner, D., Isacoff, E.Y. Woolley, G.A. (2014). Long wavelength optical control of glutamate receptor ion channels using a tetra-orthosubstituted azobenzene derivative. Chem Commun, 50, 14613-14615.

Salas, R., Pieri, F., Fung, B., Dani, J.A., De Biasi, M. (2003). Altered anxiety-related responses in mutant mice lacking the beta4 subunit of the nicotinic receptor. J Neurosci, 23, 6255-6263.

Salas, R., Pieri, F., De Biasi, M. (2004). Decreased signs of nicotine withdrawal in mice null for the beta4 nicotinic acetylcholine receptor subunit. $J$ Neurosci, 24, 1003510039.

Salas, R., Sturm, R., Boulter, J., De Biasi, M. (2009). Nicotinic receptors in the habenulo-interpeduncular system are necessary for nicotine withdrawal in mice. J Neurosci, 29, 30143018.

Sandoz, G., Levitz, J., Kramer, R.H., Isacoff, E.Y. (2012). Optical control of endogenous proteins with a photoswitchable conditional subunit reveals a role for TREK1 in GABAB signaling. Neuron, 74, 1005-1014.

Schönberger, M., Trauner, D. (2014). A photochromic agonist for $\mu$-opioid receptors. Angew Chem Int Ed Engl, 53, 32643267 .

Schönberger, M., Althaus, M., Fronius, M., Clauss, W., Trauner, D. (2014). Controlling epithelial sodium channels with light using photoswitchable amilorides. Nat Chem, 6 , 712-719.

Sheridan, R.E., Lester, H.A. (1982). Functional stoichiometry at the nicotinic receptor. The photon cross section for phase 1 corresponds to two Bis-Q molecules per channel. J Gen Physiol, 80, 499-515.

Shields, B.C., Kahuno, E., Kim, C., Apostolides, P.F., Brown, J. Lindo, S., Mensh, B.D., Dudman, J.T., Lavis, L.D., Tadross, M.R. (2017). Deconstructing behavioral neuropharmacology with cellular specificity. Science, 356 .

Silman, I., Karlin, A. (1969). Acetylcholine receptor: covalent attachment of depolarizing groups at the active site. Science, $164,1420-1421$.

Stein, M., Middendorp, S.J., Carta, V., Pejo, E., Raines, D.E., Forman, S.A., Sigel, E., Trauner, D. (2012). Azo-propofols: photochromic potentiators of GABAA receptors. Angew Chem Int Ed Engl, 51, 10500-10504.
Stein, M., Breit, A., Fehrentz, T., Gudermann, T., Trauner, D. (2013). Optical control of TRPV1 channels. Angew Chem Int Ed Engl, 52, 9845-9848.

Szobota, S., Gorostiza, P., Del Bene, F., Wyart, C., Fortin, D.L., Kolstad, K.D., Tulyathan, O., Volgraf, M., Numano, R., Aaron, H.L., Scott, E.K., Kramer, R.H., Flannery, J.G., Baier, H., Trauner, D., Isacoff, E.Y. (2007). Remote control of neuronal activity with a light-gated glutamate receptor. Neuron, 54, 535-545.

Taly, A., Corringer, P.-J., Guedin, D., Lestage, P., Changeux, J.P. (2009). Nicotinic receptors: allosteric transitions and therapeutic targets in the nervous system. Nat Rev Drug Discov, 8, 1-18.

Tapper, A.R., McKinney, S.L., Nashmi, R., Schwarz, J., Deshpande, P., Labarca, C., Whiteaker, P., Marks, M.J., Collins, A.C., Lester, H.A. (2004). Nicotine activation of alpha4* receptors: sufficient for reward, tolerance, and sensitization. Science, 306, 1029-1032.

Tochitsky, I., Banghart, M.R., Mourot, A., Yao, J.Z., Gaub, B., Kramer, R.H., Trauner, D. (2012). Optochemical control of genetically engineered neuronal nicotinic acetylcholine receptors. Nat Chem, 4, 105-111.

Tochitsky, I., Polosukhina, A., Degtyar, V.E., Gallerani, N., Smith, C.M., Friedman, A., Van Gelder, R.N., Trauner, D., Kaufer, D., Kramer, R.H. (2014). Restoring visual function to blind mice with a photoswitch that exploits electrophysiological remodeling of retinal ganglion cells. Neuron, 81, 800-813.

Tolu, S., Eddine, R., Marti, F., David, V., Graupner, M., Pons, S., Baudonnat, M., Husson, M., Besson, M., Reperant, C., Zemdegs, J., Pagès, C., Hay, Y.A.H., Lambolez, B., Caboche, J., Gutkin, B., Gardier, A.M., Changeux, J.-P., Faure, P., Maskos, U. (2012). Co-activation of VTA DA and GABA neurons mediates nicotine reinforcement. Mol Psychiatry, 18, 382-393.

Vaziri, A., Emiliani, V. (2012) Reshaping the optical dimension in optogenetics. Curr Opin Neurobiol, 22, 128-137.

Volgraf, M., Gorostiza, P., Numano, R., Kramer, R.H., Isacoff, E.Y., Trauner, D. (2005). Allosteric control of an ionotropic glutamate receptor with an optical switch. Nat Chem Biol, 2 , $47-52$

Volgraf, M., Gorostiza, P., Szobota, S., Helix, M.R., Isacoff, E. Y., Trauner, D. (2007). Reversibly caged glutamate: a photochromic agonist of ionotropic glutamate receptors. J Am Chem Soc, 129, 260-261.

Walters, C.L., Brown, S., Changeux, J.-P., Martin, B., Damaj, M.I. (2006). The beta2 but not alpha7 subunit of the nicotinic acetylcholine receptor is required for nicotine-conditioned place preference in mice. Psychopharmacology, 184, 339-344.

Wassermann, N.H., Erlanger, B.F. (1981). Agents related to a potent activator of the acetylcholine receptor of electrophorus electricus. Chem Bioll Interact, 36, 251-258.

Wassermann, N.H., Bartels, E., Erlanger, B.F. (1979). Conformational properties of the acetylcholine receptor as revealed by studies with constrained depolarizing ligands. Proc Nat Acad Sci USA, 76, 256-9.

Wonnacott, S., Barik, J. (2007) Nicotinic ACh Receptors. Tocris Reviews, 28, 1-20.

Wu, J., Liu, Q., Tang, P., Mikkelsen, J.D., Shen, J., Whiteaker, P., Yakel, J.L. (2016). Heteromeric /7b2 Nicotinic acetylcholine receptors in the brain. Trends Pharmacol Sci, 37, 562-574.

Wyart, C., Del Bene, F., Warp, E., Scott, E.K., Trauner, D., Baier, H., Isacoff, E.Y. (2009). Optogenetic dissection of a behavioural module in the vertebrate spinal cord. Nature, 461, 407-410. 
Xu, W., Gelber, S., Orr-Urtreger, A., Armstrong, D., Lewis, R. A., Ou, C.N., Patrick, J., Role, L., De Biasi, M., Beaudet, A.L. (1999). Megacystis, mydriasis, and ion channel defect in mice lacking the alpha3 neuronal nicotinic acetylcholine receptor. Proc Nat Acad Sci USA, 96, 5746-51.

Young, J.W., Finlayson, K., Spratt, C., Marston, H.M., Crawford, N., Kelly, J.S., Sharkey, J. (2004). Nicotine improves sustained attention in mice: evidence for involvement of the alpha7 nicotinic acetylcholine receptor. Neuropsychopharmacology, 29, 891-900.

Yue, L., Pawlowski, M., Dellal, S.S., Xie, A., Feng, F., Otis, T.S., Bruzik, K.S., Qian, H., Pepperberg, D.R. (2012). Robust photoregulation of GABAA receptors by allosteric modulation with a propofol analogue. Nat Commun, 3, 1095.
Zhou, X.X., Pan, M., Lin, M.Z. (2015). Investigating neuronal function with optically controllable proteins. Front $\mathrm{Mol}$ Neurosci, 8, 37.

Zoli, M., Pistillo, F., Gotti, C. (2015). Diversity of native nicotinic receptor subtypes in mammalian brain. Neuropharmacology, 96, 302-311.

Zussy, C., Gómez-Santacana, X., Rovira, X., De Bundel, D., Ferrazzo, S., Bosch, D., Asede, D., Malhaire, F., Acher, F., Giraldo, J., Valjent, E., Ehrlich, I., Ferraguti, F., Pin, J.-P., Llebaria, A., Goudet, C. (2016). Dynamic modulation of inflammatory pain-related affective and sensory symptoms by optical control of amygdala metabotropic glutamate receptor 4. Mol Psychiatry, doi: 10.1038/mp.2016.223. (sous presse) 